\author{
Review Article
}

Favourate Y Sebele Mpofu*

\title{
Informal Sector Taxation and Enforcement in African Countries: How plausible and achievable are the motives behind? A Critical Literature Review
}

https://doi.org/10.1515/openec-2020-0114

received December 19, 2020; accepted June 18, 2021.

\begin{abstract}
Taxation is a fundamental tool for revenue generation, economy building and sustainability, reducing market externalities, regulating trade, stimulating representation and achieving tax justice as well as building state accountability and responsiveness. The informal sector in developing countries has been considered a hindrance to effective domestic revenue mobilisation, hence the rejuvenated focus to bring the sector into the tax baskets. Through a critical literature review, this study sought to identify the varying motivations tabled by the various stakeholders (policymakers, scholars and tax administrators) in literature on the need to administer tax on this sector and to strengthen enforcement and to evaluate the plausibility of these motives critically. Literature search was done through Google scholar and this was also aided by snowballing. The motives were aggregated into five major groups: the magnitude of the sector and revenue implications, growth motive, the governance gains, equity considerations and the boosting of tax morale and compliance in the formal sector. This study, therefore, conducted a profound evaluative analysis of literature on these motivations, pinpointing any voids that future research could address and accordingly sought to contribute to the guidance offered to policymakers on how to improve IS taxation. In order to balance the mobilisation of revenue needs and the sector's contribution to other government objectives such as those outlined in the United Nations Sustainable Goals 1, 8 and 10 on poverty, decent work and economic growth, and reduced inequalities, governments and policymakers need to make an informed analysis.
\end{abstract}

Keywords: Informal sector taxation; growth; governance; revenue; tax morale; equity.

\section{Introduction}

Public Finance is essential for economic growth in a sustainable manner in any economy as well as to fund government expenditure in infrastructural development, security and fulfil other social obligations. Finance can take two forms: domestic and international finance (aid, donor funding and loans) (Ndaka, 2017). Domestic revenue mobilisation has become topical in contemporary development agendas because of four major aspects (Daude, Gutierrez \& Melguizo 2013). These are outlined as: (1) fiscal financing, investment and efforts by governments to fulfil their development targets and plans, need revenue (2) domestic revenue generation to finance economic and social development objectives might be a tool to enrich domestic capacity and capabilities as well as solidify domestic institutional environments (3) state legitimacy, security and national development demands ownership of domestic priorities (4) internal state accountability as well as effective and efficient state building can be improved if citizens are responsible for government financing (Daude et al., 2013:13; Sebele-Mpofu, 2020). Taxation is one crucial way through which government can mobilise revenue and it is said to be at the core of the implicit social contract between the state and its citizens. Taxation has thus become a focal point in platforms like the African Tax Administration Forum (ATAF), Africa

*Corresponding author: Favourate Y Sebele Mpofu, NUST, Zimbabwe, Bulawayo, Bulawayo Metropolitan, Zimbabwe, E-mail: favourate. sebele@nust.ac.zw 
Tax Justice Network (A-TJTN) and the Addis Tax Initiative (ATI) among others (Kundt, 2017a, 2017b; Spotlight, 2012). Transparent, equitable and efficient taxation frameworks and systems that ultimately culminate into effective domestic revenue mobilisation are argued to be critical in the achievement of Sustainable Development Goals (SDGs) in African Countries (Kundt, 2017a).

In most African countries, effective domestic revenue generation is said to be crippled by the presence of a huge informal sector (from here onwards IS) (Makochekanwa, 2020; Meagher, 2018; Sebele-Mpofu \& Msipa, 2020). The IS in Africa is overwhelming, comprising of the majority of microenterprises and small businesses as well a vast portion of employment (Benjamin\& Mbaye, 2020; Jedwab \& Vollrath, 2019). IS tax administration and policy have featured in contemporary discussions on how to mobilise more revenue for the struggling developing country governments in particular. Taxation is not only a tool for revenue mobilisation, it can be equally considered as one to foster redistribution of wealth, minimise inequality and stimulate representation amongst the citizens of any country (Bongwa, 2009; Meagher, 2018; Rogan, 2019). Intense debate has arisen on whether IS taxation and enforcement should be prioritised by these out of revenue SSA governments (Joshi, Prichard, \& Heady, 2013, 2014; Resnick, 2019; Rogan, 2019). Those advocating for taxation and enforcement have cited the magnitude of the sector and its continued growth, the potential to mobilise more tax revenue, reap growth and governance gains (Joshi \& Ayee, 2002; Joshi et al., 2014; Makochekanwa, 2020). The opponents against taxing the IS have tabled equally pragmatic arguments, questioning the attainability of the revenue, governance and growth gains, suggesting the likelihood of pervasive effects on governance and growth and arguing that increase in revenue is less likely too, due to potentially high costs of collecting (Kanbur \& Keen, 2014; Meagher, 2018; Meagher \& Lindell, 2013; Pimhidzai \& Fox, 2011; Sebele-Mpofu, 2020). In SSA an increasingly intricate array of presumptive taxes have been implemented.It is estimated that around $65 \%$ of Africa's tax authorities have adopted one system of presumptive tax or another (Resnick, 2020a). These include fixed monthly presumptive tax rates (Zimbabwe) and tax on turnover (TOT) (South Africa, Kenya, Zambia and Tanzania among others). These presumptive tax adoptions have been motivated by different reasons and objectives. This study through a comprehensive literature review of studies on IS taxation in developing countries and African countries in particular (Carroll, 2011; Kundt, 2017a; Resnick, 2019; Rogan, 2019) University of Dares Salaam, Department of Economics (UDSM, DoE), 2018), among others takes a reflective analytic review of the question, Should IS taxation and enforcement be a matter of priority? How accomplishable are the motives behind taxing the IS, is also another major question that begs for answers. The study identified five major reasons for taxing the IS in African countries, which are: revenue mobilisation, boosting growth through formalisation, strengthening governance, ensuring equity in taxation and increasing tax morale. The study reviews literature on the motivations behind taxing the IS and evaluates the cogency of these in line with the findings in the various studies on the fulfilment or non-achievement of these objectives. This study was motivated by researchers such as Joshi et al. $(2013,2014)$ and Kundt $(2017 a)$ who point out to the benefits of revenue, governance and growth as likely to accrue but are quick to note that these remain insufficiently explored or justified. Kundt (2017a:3) specifically states in relation to the growth and governance effects of IS taxation that, "there is no strong empirical support in the literature (research gap)". The researcher further submits that in relation to the ability of IS taxation to enrich political dialogue and collective bargaining, "empirical evidence on the effects are limited (research gap)" (Kundt, 2017a:3). Therefore, through a literature review of prior and recent studies on IS taxation and their findings, this study accentuates the research gaps pointed out by Kundt (2017a) and Joshi et al. (2013, 2014). Through a synthesised presentation of findings and implications from the reviewed studies, this study also explicates some more research gaps and directions for further research. Furthermore, the current study addresses the divergent views related to each motivation for taxing the IS in order to assess the feasibility of taxing the sector. Heggstad et al. (2011) and Machemedze et al. (2018) consider research to be a crucial tool in policymaking, evaluation and amelioration. Section 1 has already explained the motivation behind the study as well as its objective. Section 2 expounds on the research methodology adopted in the study. Section 3 follows with a literature review to contextualise the IS in African countries, discussing the reasons behind crafting taxation legislation towards its taxation. The objective of the section is to fully evaluate the justifiability or unjustifiability of taxing the sector from the perspective of different previous scholars. Section 4 discusses and synthesises findings on the motives for taxing the IS and the potency or validity of these findings as established in the previous studies. Section 5 provides the conclusions, recommendations and areas of further research. 


\section{Research Methodology}

This paper is a review article. According to Hughes, Davis, and Imenda (2019:25), a "theoretical paper draws evidence from a critical review of relevant literature". Rigorous reviews and knowledge syntheses remain indispensable dimensions of research for five main reasons: (1) discerning what has been discussed and published on the topic under investigation (2) showing the extent to which the current research on the topic unveils and communicates any interpretable outcomes and trends (3) collating empirical findings to a leaner or more focused question (4) building new frameworks, models and theories (5) pinpointing areas, topics, questions, assertions, assumptions, claims and findings that need further exploration, investigation or analysis (Pare, Trudel, Jaana \& Kitsiou, 2015). There are several types of reviews that can be conducted, such as narrative, systematic, scoping, semi-systematic and critical reviews. These differ in terms of the main goal or purpose, search strategy adopted as well as the way the appraisal, analysis and synthesis are carried out (Grant \& Booth, 2009; Snyder, 2019). This study therefore adopted the critical review approach or "integrative literature review" as described by Snyder (2019:334). A critical review seeks to conduct a critical evaluation and interpretive analysis of existing literature on a chosen topic of interest. The in-depth assessment of literature is also aimed showing contradictions, consistencies and inconsistencies (Grant \& Booth, 2009; Mpofu, 2021). The literature evaluation is also intended to reveal strengths and weaknesses as well as controversies and other fundamental aspects with regards to theories, methodologies and findings in the area being explored (Paret et al., 2015, Snyder, 2019). This study, therefore, carried out an appraisal of contemporary literature on IS taxation with specific focus on the motivations behind the renewed attention on the prospects of taxing the sector and avenues towards the implementation of IS tax policies in developing countries and SSA in particular. The paper provides a counterbalanced and objective synopsis, review and synthesis of arguments and literature from previous but recent research in order to evaluate the current body of knowledge on IS taxation and justifications for its adoption. Akintoye (2017) posits that literature review informs readers of the current trends, models, concepts and state of knowledge in a subject area under study. Therefore, the main objective of this study was to put into perspective current and novel inclinations as well as to pinpoint research lacuna in the subject area of IS taxation and enforcement motivations as explored from the different studies.

The resultant outcomes could possibly galvanise and provoke new conceptions that have been unexplored or weakly documented. These ideas and identified research gaps could be addressed through further research on how a better conceptualisation of the topic or viewpoints can be achieved as well as through invigorating or redesigning of policy strategies, tax systems, structures and implementation routes. Important decisions with regards to the methodology for this review, concerned having a clearly formulated research question, decisions on the databases to be searched and the inclusion and exclusion criteria of the articles found as suggested by Mpofu (2021). The other vital considerations involved, the determination of the right boundaries for the review, selection of what information to extract, how to analyse, synthesis, report the findings and show the researcher's own contribution (Snyder, 2019; Pare et al., 2015). After reading comprehensively on taxing the IS and exploring the "areas for further or future research" sections in studies, the researchers found the need to explore the potency of the motivations of taxing the sector hence formulation of the research question, how plausible and achievable are these motives? Journal articles were searched for through the Google scholar database (peer-reviewed articles), with the key main terms and phrases used to search being "motives for IS taxation, reasons for taxing the informal sector or questions such as, what drives IS taxation? Should the IS be taxed? Appendix 1 provides a list of the exact search key terms and phrases. In light of the fact that IS taxation is still an under-researched area, conference papers and working papers relevant to the study were also reviewed to enhance the breadth of the study. All the papers found were reviewed, with special focus on the abstract, keywords and introduction (background of the study) and those that addressed the motives, justification and rationale for taxing the IS were chosen. The selected studies were restricted to papers that focused on addressing the question of the plausibility and achievability of the motives for taxing the IS. The papers were screened based on time basis, selecting the most recent studies considering the renewed focus (a ten-year range from 2010 to 2020), a few old articles were available (Bongwa, 2009; Joshi and Ayee, 2002, 2008; Leoprick, 2009, Prichard, 2009) and these were reviewed in order to get contextual background information on taxation of the IS. Considering that IS taxation research domain is considered an immature research areas that has just gained renewed attention in recent years in developing countries (Joshi et al., 2014; Rogan, 2019), it was necessary to complement the database searches with snowballing (Jalali \& Wohlin, 2012), which is often described as "pearl mining, growing, citation analysis, reference searching or citation mining” (Padron, 2018). 
For this research, snowballing was undertaken as follows: firstly, the search from the Google scholar database provided the preliminary papers. Secondly, from the starting papers the researchers conducted backward snowballing (going backward by analysing the reference list) of the relevant articles previously identified, basing on the title of the papers and the earlier set time guidelines relevant articles were chosen and reviewed). Thirdly, forward snowballing was also used, going forward by pinpointing articles citing the articles previously identified in step one and two (Jalali \& Wohlin, 2012). Considering IS taxation is an emerging area, the three methods largely brought almost the same studies. For example Joshi et al. (2013, 2014), Joshi and Ayee (2002, 2008), Prichard (2009) and Dube (2014) were found to be widely cited amongst studies (Kundt, 2017a, b; Ligomeka, 2019, Newman, 2019; Resnick, 2019; Rogan, 2019), as they are among the earlier studies on IS taxation. Backward snowballing allowed the researcher to attain an in-depth understanding of IS taxation and what triggered the need to focus on it for the early researchers such as Joshi and Ayee (2002). On the other hand, forward snowballing helped the researcher locate current studies on the topic and gain a clearer picture of the IS taxation phenomenon, especially who was currently researching it and what they were concentrating on. In addition, the researcher selected the most cited scholars on informal sector taxation in Google Scholar and performed a forward search on them. For these leading scholars on IS taxation such as Dube (2014); Prichard (2009); Meagher and Lindell (2013) and Joshi and Ayee (2002, 2008), the researcher performed author forward search to find more recent works from these authors and this resulted in relevant articles published around 2010 to 2020. This was also vital in enhancing a deeper and wider understanding, giving the researcher the capacity to draw any consistencies and inconsistencies in literature. The backward and forward searches allowed for an even better assessment where quotations were used in some studies, as they could be traced back to the original article and context. In total, 55 studies were found relevant and reviewed. Wee and Banister (2016) suggest a range of between 30 and100 studies to be enough for a review article. Analysis was semi-systematic as the researcher sought to evaluate literature according to the research contributions made. This was done after having categorised the motivations and brought together similar and overlapping reasons into one broad group. This study settled for five categories of motivations (revenue generation, formalisation and growth, strengthening governance, reducing inequality and boosting tax morale). Padron (2018) and Snyder (2019) emphasise the need to organise the reviewed literature on the basis of concepts, themes, and relationships established during the review process to give the research some measure of chronology and standardisation. The synthesis was purely qualitative in nature following a chronological order as the analysis sought to identify conceptual contributions made by the different researchers. The researcher sought to bring a balanced analytic review that accentuated the various researchers' perspectives, but at the same time not drowning the researcher's own voice and thoughts. The methodology described above was guided by submissions by Grant and Booth (2006) and Snyder (2019). Its potential weaknesses could be the risk of same author bias emanating from snowballing or forward search of leading scholars and researcher bias due to experience in the area and knowledge of the leading scholars. The combination with database search was meant to alleviate the likelihood of these potential biases and the researcher tried to review the articles as objectively as possible.

Direct quotations, from the different researchers were used where necessary as tools for clarification, emphasis and thought provocation as advocated for by Dai, Free, and Gendron (2016) and Morse (2015). Figure 1 sets out themes for this research. The thematic framework explicates the route followed by the research and "grounds it firmly in theoretical constructs" (Adom, Hussein, \& Agyem, 2018:438), just like a theoretical framework. Adom et al. (2018) recommend that theoretical and conceptual frameworks must connect well with the research process, definition of terms, the problem statement and the reviewed literature for a particular study. These frameworks must also link well with how the findings were discussed and presented, the conclusions drawn and recommendations made. Accordingly, the thematic framework is the glue that binds this study.

This framework provides guidance on how literature was reviewed and also how the findings were discussed. IS taxation is driven by the five justifications as presented in Figure 1 and the accomplishment of these motives (objectives) determines the effectiveness and efficiency of the IS taxation framework used. The prioritisations of the objectives will differ on a country to country setting. The studies reviewed had a focus on the motivations behind the need to tax the IS and implementation of presumptive taxes to tax the IS as schematically portrayed in Figure 1. Their findings and recommendations in relation to these motives are presented and discussed in the next section. 


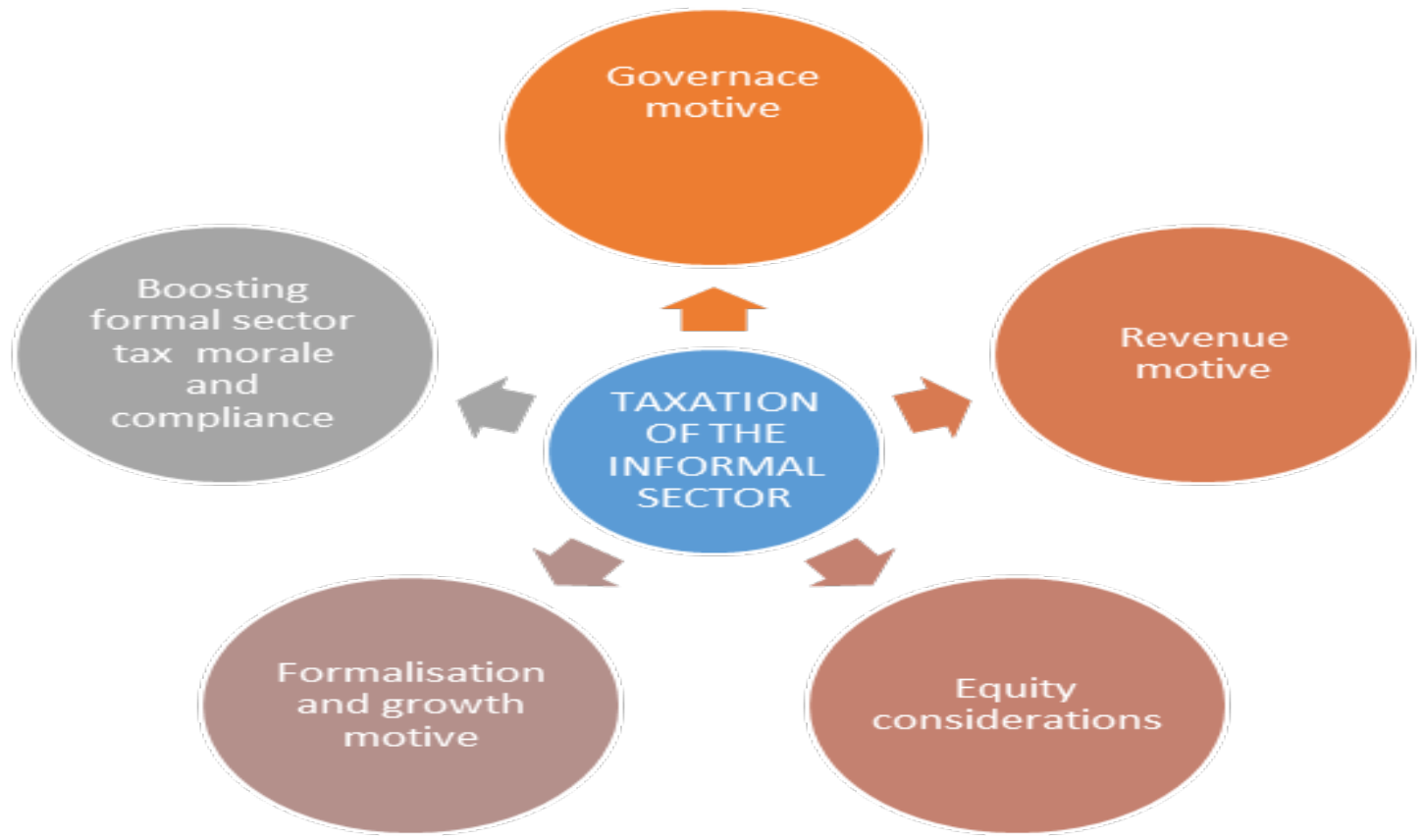

Figure 1: Themes guiding the review. Source: Own Compilation

\section{The IS Defined and Explained}

The Institute of Economic Affairs (IEA), Budget Focus (2012), describes the IS as comprising of activities not governed by regulations such as environmental, tax and labour laws, but are often subjected to governance and regulation by local authorities and these are neither normally monitored nor included in Gross Domestic Products (GDP) of Countries. The UDSM, DoE (2018) explains the sector as one characterised by a high degree of lack of regulation by the state, cash transactions and poor accounting, as well as the absence of records. Bongwa (2009) refers to it as the "hard to tax," and according to Mbilinyi and Mutalemwa (2010:1), the sector is largely comprised of unregistered and difficult to tax groups, which include "small scale traders, farmers, small manufacturers, craftsmen, individual professionals and many small scale businesses". Others describe it as the hidden, the shadow and the underground economy, among other descriptions. There is no agreement on how the IS is defined but researchers converge on one commonality (Sebele-Mpofu \& Msipa, 2020), this being the acknowledgement that the IS is diverse, ubiquitous, burgeoning in developing countries and that it covers some crucial sectors in the business world, which include retail, manufacturing and construction among other sectors (Benjamin \& Mbaye, 2014; Kundt, 2017a; Pimhidzai \& Fox, 2011).

The actual magnitude of the sector is difficult to estimate because the figures commonly presented in literature are fraught with controversy, often disputed and strongly criticised because of the scarcity in data, the hidden nature of the sector and the political linkages to the sector (Kundt, 2017a). The IS is estimated to be contributing around 35-50\% of GDP in developing countries (Joshi et al, 2014; Maina, 2017). The IS in low income countries is described as two times the size of the same sector in OECD countries. The sector is estimated to be biggest in Latin America and the Caribbean Region, contributing about 39.9\%, followed by SSA with 37.8\%, East Asia with 22.1\%, and lastly, the OECD countries (Kundt, 2017a; Schneider \& Buehn, 2018). In compatibility of opinions, Medina and Schneider (2018) estimate Bolivia (in Latin America) to have the largest IS in the world with an estimated GDP contribution of about 63\% followed by Zimbabwe (in SSA), with a GDP contribution of around 60\%. Dickerson (2014) submits that the IS creates 30\% of worldwide GDP and conservatively 40 to $60 \%$ of SSA economy (Dickerson, 2014). Bhorat, Naidoo, and Ewinyu (2017) expostulate that the IS presently occupies a pivotal position in developing countries, contributing around 50 to $80 \%$ of GDP of these developing nations, representing a larger portion of employment of about 60 to $80 \%$ and $90 \%$ of new jobs. Table 1 below adapted from the IEA's Budget Focus presents a comparative display of the IS characteristics in the OECD countries and Developing Countries. 
Table 1: Characteristics of the IS in High-income countries and Low-income developing countries.

\begin{tabular}{lll}
\hline Factor & High-income OECD country & Low-income country \\
\hline Employment and GDP & $\begin{array}{l}\text { About 10\% to 20\% of employment and GDP in } \\
\text { the IS. }\end{array}$ & $\begin{array}{l}\text { Up to } 50 \% \text { of GDP, but higher share of employment } \\
\text { approximately } 90 \% .\end{array}$ \\
Tax Compliance & $\begin{array}{l}\text { Non-compliance is mainly due to failure to comply } \\
\text { with formal sector legal requirements (criminal } \\
\text { activity, tax and regulation evasion). }\end{array}$ & $\begin{array}{l}\text { Non-compliance mainly driven by inadequate capacity } \\
\text { to comply, illiteracy, innumeracy and weak specific } \\
\text { accounting and tax compliance capacities }\end{array}$ \\
$\begin{array}{l}\text { Concentration of tax non- } \\
\text { compliance }\end{array}$ & $\begin{array}{l}\text { Non-compliance with tax concentrated in self- } \\
\text { employed service and moonlighting, cash or } \\
\text { undocumented employment. }\end{array}$ & $\begin{array}{l}\text { Significant share (5\%-30\%) in non- monetary subsis- } \\
\text { tence sector. }\end{array}$ \\
& $\begin{array}{l}\text { Rural (agriculture and trading) and growing urban } \\
\text { sectors (trading personal services, food and beverage } \\
\text { services, petty and manufacturing). }\end{array}$ \\
Income levels & Income levels at or above formal sector. & Below average income levels. \\
Social Security & $\begin{array}{l}\text { Social security payroll taxes provide major incen- } \\
\text { tive for untaxed informal employment. }\end{array}$ & $\begin{array}{l}\text { Social Security payroll taxes insignificant, most below } \\
\text { the minimum income tax threshold }\end{array}$ \\
\hline
\end{tabular}

Source: IEA Budget Focus (2012)

The summary above is also open to criticism as it describes the IS as small-scale activities with low incomes undertaken by the vulnerable sector of society with low literacy levels yet in Zimbabwe, the IS is described as a mixed bag or a continuum. The sector comprises of both the vulnerable with low incomes and the highly privileged with high incomes who are in the sector to evade tax and often aided by political connections (Mashiri, 2018; Sebele-Mpofu \& Msipa, 2020). The sector is often comprised of small-scale traders, small-scale manufacturing operations, garage owners, restaurants, small-scale miners and repair workshops among others. The contemporary setup has been inclined towards individual professionals such as lawyers, doctors, accountants, economists and engineers being players in this sector (Fajnzylber, Maloney, \& Montes-Rojas, 2009). In West Africa, Benjamin and Mbaye (2012), posit that there are large informal companies resembling formal companies in all facets such as fixed abode and having bank loans, but these do not contribute to the tax basket. These are often either structured as small informal firms to conceal them from tax authorities or are shielded by politicians from tax authorities. In Tanzania, Mbilinyi and Mutalemwa (2010) advance that, although it could not be established with certainty, the Tanzania Revenue Authority (TRA)'s lack of aggressiveness in bringing more IS taxpayers into the tax net was due to the fact that some of the business were owned by the political powerful individuals. In Uganda, Pimhidzai and Fox (2011) advance that there is no evidence of the existence of such large firms and tax evasion as described by Benjamin and Mbaye (2012) and actually describe the existence of the lowincome firms described by the IEA's Budget Focus (2012).

Despite the controversial debates on the sector, there is consensus that tax policy debates, design and research has to focus on how to broaden the tax base by including the IS into the tax net (Dube \& Casale, 2016; Kundt, 2017a; Mpapale, 2014; Sebele-Mpofu \& Msipa, 2020) or perhaps how to boost tax morale in the sector (Bitzenis \& Vlachos, 2018; Dickerson, 2014; Sebele-Mpofu, 2020). The next section focuses on informal sector and taxation literature.

\subsection{Taxation and the Informal sector}

From the introductory discussions on the magnitude of the IS in developing countries, Africa and SSA countries, the statistics though controversial, point to a large and growing IS which makes it challenging for low-income countries to mobilise enough funds for sustainable development financing from taxation (Heggstad, Ustvedt, Myhrvold-Hanssen, \& Briseid, 2011; Kundt, 2017a; Ligomeka, 2019; Mpapale, 2014). On the other hand, the magnitude of the sector offers a worthwhile opportunity to widen the tax base and indirectly facilitate the graduation of informal businesses into the formal sector and minimise the impediments to formalisation (IEA's Budget Focus, 2011). Researchers have offered contradictory opinions on taxing the IS. Some researchers point to the fact that very minute amounts if any 
are transferred from the income made in the IS to state coffers as tax and that non taxation of the sector results in substantial revenue losses and leakages (Joshi et al., 2014; Makochekanwa, 2020; Mbilinyi \& Mutalemwa, 2010). Notwithstanding these arguments, others dispute these assertions, arguing that the IS contributes to the revenue baskets of these governments through various ways such as formal taxes (VAT, customs duty and sales tax among others) (Dalu, Maposa, Dalu, \& Pabwaungana, 2013), regressive taxes such as local fees, licences fees and other local levies (Newman, 2019; Rogan, 2019) and informal taxes such as bribes, payments to land barons and other cartels (Meagher, 2018). Therefore any further taxing is deemed rather unfair, oppressive and detrimental to the sector's profitability and continued survival (Ligomeka, 2019; Meagher, 2018; Meagher \& Lindell, 2013; Pimhidzai \& Fox, 2011) as well as perpetuation of income inequality (UDSM, DoE, 2018). Despite the bribes not contributing to the revenue basket, these come from the incomes of the IS, hence increasing their business costs. Several researchers have also submitted various challenges to be surmounted if ever the IS can be successfully and fairly taxed. Some of these include: the mobile and nebulous nature of the sector, high collection costs, aggressiveness of operators, cash transactions, poor recordkeeping, capacity constraints, multiplicity of taxes, complexity of tax systems and lack of stakeholder engagements among other challenges (Mbilinyi \& Mutalemwa, 2010; Sebele-Mpofu \& Chinoda, 2019; Sebele-Mpofu \& Msipa, 2020). Formidable as these constraints appear to be, governments have not been deterred to make attempts towards effectively and efficiently taxing the sector, very important reasons must be driving this renewed focus towards taxation of the IS (Getachew, 2019; Ndaka, 2017; Resnick, 2019; Rogan, 2019).

\subsection{Reasons for Advocating for Prioritising IS Taxation}

Several authors have offered different rationale for taxing the IS (Kundt, 2017a, 2017b; Makochekanwa, 2020; Rogan, 2019). These justifications have generated a lot of disagreements among researchers (McKenzie \& Sakho, 2010; McKenzie \& Paffhausen, 2017; Meagher, 2018; Pimhidzai \& Fox, 2011), hence the need to evaluate the validity of these reasons for taxing the sector as offered by various scholars. These reasons have been broadly packaged by some scholars as the revenue, growth and governance gains (Joshi et al., 2013, 2014; Kundt, 2017a; Makochekanwa, 2020; Meagher, 2018; Rogan, 2019) and narrowly broken down by others into: the need to formalise the IS, the revenue mobilisation requirements, the phenomenal size and growth of the IS, the effect on the tax compliance and or tax morale of the formal sector, state legitimacy, demands from formal firms, the tax and accountability links and to address income inequalities (Bongwa, 2009; Mpapale, 2014; Ndaka, 2017; Ogbuabor, Aneke, \& Ogbuabor, 2014; Okoye, Akenbor, \& Obara, 2012; UDSM, DoE, 2018). In Zimbabwe (Ligomeka, 2019; Newman, 2019; Sebele-Mpofu \& Msipa, 2020) refer to three major objectives of taxing the IS outlined by the Government of Zimbabwe (2005) and Ministry of Finance and these are: to widen the narrow tax base, mobilise more revenue for the government and champion the equity principle of taxation which is one of the cornerstones of a fair tax system. The study explored these justifications for IS taxation advocacy and implementation. These will be fused together as seen fit by the researcher as some are overlapping in focus, one being a branch or child node of the other. For example, governance and legitimacy. These are evaluated in detail in the subsections that follow.

\subsubsection{The Magnitude of the IS and Revenue mobilisation (to curb revenue losses)}

The IS is arguably burgeoning in developing countries. The estimation though not very accurately exhibits that the sector in Africa accounts for "about 78 percent of non-agricultural employment and 61 percent of urban employment is in the informal sector and a massive 93 percent of new jobs are created in the in the informal sector", yet the sector is described as contributing very little to the tax revenue basket of economies (Carroll, 2011:5). Rogan (2019) adduces that the desire to mobilise more tax revenue through the inclusion of the IS into the tax basket is conceivably, the major reason for IS tax administration in the majority of developing countries. In affirmation, UDSM, DoE (2018) expresses that the informal sector displays an erratic pattern in contributing to the national tax basket, and therefore, revenue lost from the sector accumulates over time. The prominence of the revenue mobilisation objective as well as the championing of the tax evasion motive as a major driver of informality is argued by other researchers to have been popularised to the impairment of constructive tax policy with regards to the sector (Sebele-Mpofu \& Mususa, 2019; Utaumire, Mashiri, 
Table 2: Studies on Selected Countries and the IS contribution to GDP.

\begin{tabular}{|c|c|c|c|c|}
\hline Country & Employment levels & $\begin{array}{l}\text { GDP contribu- } \\
\text { tion Estimation }\end{array}$ & $\begin{array}{l}\text { Tax Revenue contribution } \\
\text { Estimation }\end{array}$ & Studies \\
\hline Kenya & $77 \%$ of employment & $34.3 \%$ & $3 \%$ of total national tax revenue & (IEA's Budget focus, 2012; Maina, 2017 \\
\hline Ghana & $\begin{array}{l}80 \% \text { to } 86 \% \text { of the } \\
\text { workforce }\end{array}$ & Over $50 \%$ & $5 \%$ of total tax revenues & $\begin{array}{l}\text { (Carroll, 2011; Mahadea \& Zogli, 2018, } \\
\text { Thompson Junior, 2014) }\end{array}$ \\
\hline Nigeria & $80 \%$ of the labour force & $50-60 \%$ & $2-4 \%$ of total tax revenues & $\begin{array}{l}\text { (Ogbuabor \& Malaolu, 2013; Udoh, } \\
\text { 2015) }\end{array}$ \\
\hline Zimbabwe & $\begin{array}{l}\text { More than } 8 \% \text { of the } \\
\text { workforce }\end{array}$ & $60.6 \%$ & $\begin{array}{l}3-6 \% \text { of total national tax } \\
\text { revenue }\end{array}$ & $\begin{array}{l}\text { (Ligomeka, 2019; Medina \& Schneider, } \\
\text { 2018) }\end{array}$ \\
\hline Zambia & $72 \%$ in Lusaka & $47.7 \%$ & $4 \%$ of total national tax revenue & $\begin{array}{l}\text { (Phiri \& Nakamba-Kabaso, 2012; } \\
\text { Resnick, 2019) }\end{array}$ \\
\hline Tanzania & Over $60 \%$ & $40 \%$ & $\begin{array}{l}\text { Around } 1.8 \% \text { of national tax } \\
\text { revenues }\end{array}$ & $\begin{array}{l}\text { (Dube \& Casale, 2016; Mbilinyi \& Muta- } \\
\text { lemwa, 2010) }\end{array}$ \\
\hline
\end{tabular}

Source: Own Compilation from Various Sources

\& Mazhindu, 2013). The motive has become the dominating objective to the point of overshadowing all other reasons for taxation in the economy such as representation, redistribution and fostering economic growth (Meagher, 2018; Pimhidzai \& Fox, 2011; Sebele-Mpofu, 2020), such that revenue collection becomes the one and only focal point of revenue authorities no matter how many livelihoods are affected or businesses' survival is constrained (Heggstad et al., 2011). Pimhidzai and Fox (2011) expostulate that in their quest for more revenues, developing countries should be cautious that the same strategy that is targeted at increased revenue generation does not result in a twofold loss. That is, the loss of the same envisaged revenues and people's livelihoods. The authors further suggest that employment opportunities maybe lost as the small businesses might suffocate from taxation and collapse, annihilating "the goose that lays the golden eggs" (Pimhidzai \& Fox, 2011:21). These interesting two sides of the coin are explored in detail in this section. Is taxing the IS a way to generate more revenue or to extinguish the sector. Moore (2020:1) posits that the argument that most of the untapped tax revenues lie in the informal sector is diversionary and a misconception. This is because the collected tax in most African countries is lost through unwarranted tax exemptions or hidden in the assets and incomes of the wealthy persons who escape tax. The conflicting outcomes are evident, hence, the question whether IS taxation is resource mobilisation or extermination of the sector.

The IS has dominated most of the biggest and quickest growing sectors such as retail, construction and manufacturing in African economies (Kundt, 2017a). The informal sector is very big and cuts across all sectors of economies, be it transport, mining, manufacturing, retail, service industries such as tourism and hospitality (Okoye et al., 2012). It is a continuum that is all inclusive of the vulnerable and professionals such as accountants, engineers, economists, carpenters, welders, mechanics, hairdressers, small scale miners and those in construction industry as well as cottage industry manufacturers among others (Maloney, 2004; Mbilinyi \& Mutalemwa, 2010; Perry et al., 2007). Rogan (2019) citing the ILO (2018), suggests that $61 \%$ of the global workforce is informally employed and in developing countries with specific focus to SSA and East Africa the IS workforce constitutes about $89 \%$ and $92 \%$ respectively. These activities constitute substantial portions of GDP in developing countries and SSA. Table 1 below is a summary of the estimations of GDP contributions in selected developing countries from selected studies, just to foreground the discussions on the revenue generation implications tabled by researchers.

If the above figures are anything to go by, non-taxation or inefficient taxation of the IS constitutes significant foregone revenues. The lost revenue by not taxing the sector and its activities in developing countries is projected to be between 35 to 55\% of total revenue (Joshi et al., 2013; Mbiliayi, 2012; Mbilinyi \& Mutalemwa, 2010) and around 4\% of the IS GDP contribution (Mpapale, 2014; Ndaka, 2017; IEA, 2012). The estimated revenue lost in Kenya was argued to be so significant and to contribute nearly 4 times the funds needed to finance Kenya's health sector budget in 2012 (Spotlight, 2012). The estimated potential revenues have to be viewed conservatively, but they signify a need to tax the sector as substantial revenues are lost. Some scholars question the authenticity of these figures (Kundt, 2017a), 
yet others say for interest sake if they are accepted, they still overlook a significant fact, the costs of collection and enforcement associated with the hard to tax (Bongwa, 2009; Joshi et al., 2013, 2014; Nakamba-Kabaso \& Phiri, 2012) and the nebulous and heterogeneous sector that is spread far and wide (Mpapale, 2014; Sebele-Mpofu \& Msipa, 2020).

This issue of the costs outweighing the benefits and defeating the value for money concept was reiterated by Kundt (2017a) and Rogan (2019) citing IMF (2011:39) expressing that "It is not uncommon for developing country tax administrations to devote large resources to (the survivalist sector) in the hope of flushing out medium or large taxpayers by blanket enforcement operations, but results have been poor and costs of implementation high". Sometimes the potentially modest revenues versus the high costs as well as the aggressive reactions of IS sector operators to revenue collectors discourages revenue collectors to dedicate time and money pursuing this risky sector (Joshi \& Ayee, 2008; Kundt, 2017a; Mbilinyi \& Mutalemwa, 2010; Machemedze et al., 2018). Tax collectors end up concentrating on the large and not so elusive formal sector, thus focusing on a narrow tax base (Getachew, 2019; Ndaka, 2017; Pfister, 2009). In a nutshell, the "direct revenue impacts of informal sector taxation and the associated costs might be highly difficult to assess as data availability and quality is poor for many developing countries" (Kundt, 2017a:5). Moore (2020:24) expresses doubt on whether broadening the tax base by including the IS would yield substantial tax revenues, otherwise their inclusion through the "registration obsession" would just add more redundant inactive taxpayers. Whether significant revenues can be mobilised from this sector remains questionable.

Other researchers argue that the tax gap is rather exaggerated (Pimhidzai \& Fox, 2011; Rogan, 2019), it is smaller than the projected 35 to $55 \%$ of total revenue tabled, because the IS is already paying tax to local authorities through levies and fees. Some of the informal firms are too small to meet the registration thresholds for formal taxes and even to pay tax to national government through VAT and/or Pay as You Earn (Meagher, 2018; Pimhidzai \& Fox, 2011; Resnick, 2019). Elaborating further, Rogan (2019) posits that this argument could be justifiable and that it might indeed be correct that the IS pays more in the form of local authority fees, levies and other operating licence payments. The challenge is the lack of reliable data and quantification of their contributions by the local authorities and city councils in their budgets. Meagher (2018) considers the tendency by governments to turn a blind eye to the multiplicity of taxes problem (formal and informal) that the IS grapples with, as "fiscal essentialism". The problem is also the failure to keep proper records by these operators in order to help justify their cases. Studies in different countries on the taxation of the IS found cogency in the argument and that indeed these payments were consuming a substantial portion of the income. In Zimbabwe, scholars point to regressivity due to IS taxation (Dube, 2018; Sebele-Mpofu \& Mususa, 2019; Utaumire et al., 2013) and in Nigeria, the mortality levels of SMEs and their depressed growth is linked to tax (Atawodi \& Ojeka, 2012; Meagher, 2018; Ojeka, 2011). Furthermore, in Zambia researchers offer mixed findings, acknowledging the potential tax gap but point to the probable pervasive outcomes of taxing the IS (Nakamba-Kabaso \& Phiri, 2012; Resnick, 2019), in Uganda, Pimhidzai and Fox (2011) empirically champion the regressive impact of the multiplicity of taxes on the IS, in Tanzania negative effects on the growth and survival of the sector is underscored (Mbilinyi \& Mutalemwa, 2010; USDM, DoE, 2018) and in Ghana, Prichard and Van den Boogaard (2017) estimate the contribution by the sector to total local government tax revenue to range between 24 to $27 \%$. Comparing the more than $24 \%$ of revenue contribution to local authorities (Prichard and Van den Boogaard, 2017) and the approximated 3\% contribution to total tax revenues of African nations advanced by Maina (2017) shows that the sector is contributing to the revenues of economies, albeit not through national tax heads. Further taxing the IS is observed to be just an addition to the multiple taxes they are already paying which will further burden them and compromise their survival, growth and profitability (Meagher, 2018; Pimhidzai \& Fox, 2011:2, 21). Perhaps the solution to the challenge of multiplicity of taxes lies with the quantification of how much the informal sector contributes to local authorities and/or governments in the form of fees, levies and other forms of tax (this signifies a crucial research gap).

The IS incomes are said to be very low and that not much revenue can be mobilised from the sector, even for those large informal firms who have the potential to contribute significantly to the tax basket, the "political economy of taxation” becomes a stumbling block (Mashiri, 2018; Meagher, 2018; Meagher \& Lindell, 2013; Resnick, 2019). The political protection accorded to some of the big informal firms will only leave a few of those who don't enjoy the privilege to be taxed (Meagher, 2018). This view of wealthy and politically connected individuals being highly "undertaxed" or not paying tax in most African countries is acknowledged by Moore (2020:24). Most African politicians are not committed to having the IS taxed risking stepping on the toes of their colleagues or even losing the substantial votes from this sector during elections (Bird, 2007, 2015; Bird \& Zolt, 2008). The problem is how to ensure political faithfulness in taxing the IS in developing countries. 
The lack of a proper database of potential taxpayers in developing countries compounds this shortage of statistics problems, stifles the crafting of proper strategic plans on how to tax the sector or mitigate the risk of noncompliance or proper forecasting (Bird, 2007; Mashiri, 2018; Prichard, 2009). Joshi et al. (2014) encourage developing countries not to solely focus on the revenue mobilisation motive and not to just focus on the short term cost-benefit analysis but to look more on the long-term benefits of nurturing and incentivising the sector to register for tax, access financing and improve productivity (Loeprick, 2009). This, in the long term, will yield the much-desired benefit of increased tax revenue and help curb the leakages as well as boost voluntary compliance. In the long run, formalisation for tax purposes might enhance overall productivity of informal firms, help them grow and contribute consequentially to the revenue basket, thus broadening the tax base (Joshi et al., 2014; Kundt, 2017a). Offering a contradictory view on the impact of formalisation on the informal sector, Fourie (2018) advances that registering informal firms for tax purposes would not bring any significant improvements to their day to day operations and viability. In affirmation, Moore (2020), calls such increased efforts towards registration for more informal firms as a registration obsession that does not increase tax collections. Fourie (2018) further tables the fact that the sector pays VAT on their purchases of inputs for making taxable supplies but do not obtain input tax refunds. Additionally, the researcher adduces that some of the firms even if formalised may be below the income tax thresholds. In Zimbabwe, IS taxation has been observed to generate negligible revenues, burden the sector unfairly through high tax rate and being regressive to growth and survival of informal firms (Dube, 2014; Ligomeka, 2019; Newman, 2019; Sebele-Mpofu \& Msipa, 2020), regressive to the growth of small firms and would potentially generate very little in terms of revenue (Pimhidzai and Fox, 2011 and Meagher, 2018 in Ghana and Nigeria respectively), perpetuate inequality and mobilise inconsequential revenues in Tanzania (USDM, DoE, 2018) and has brought little success in mobilising revenues in Kenya (Maina, 2017). Whether these envisaged long-term benefits of heightened tax revenue collections, due to the inclusion of the IS in the tax net are achieved, remains weakly investigated and justified empirically.

\subsubsection{Formalisation of the IS and improving growth}

Formalising of IS activities has been advocated for in various development agenda platforms such as the Addis Ababa Action Agenda (Kundt, 2017a), International organisations such as the International Monetary Fund and the World Bank (Spotlight, 2012; IMF, 2011). Various researchers have proposed that such formalisation will result in improved productivity, growth, survival and profitability of IS activities and firms in the sector (Joshi et al., 2014; Loeprick, 2009). Kundt (2017a:3) calls for the need to "encourage formalisation and growth of micro, small and medium-sized enterprises in order to promote sustainable and inclusive growth". The formalisation argument, especially IS taxation and growth gains link remains "perhaps the least developed in the tax literature" (Rogan, 2019). The growth gains argument hinges on the belief that the IS is a seedbed for the formal sector and those in the IS are there with the sole objective of "growth and expansion" into the formal sector, which is not really the case (Rogan, 2019). In light of such arguments as the ones above, Rogan (2019) questions the relevance of the growth implications standpoint and its appropriateness when contextualised to those with the largest IS in the world. These include developing economies in Asia, the Caribbean, Latin America and Sub-Saharan Africa, where the growth of the IS is arguably motivated by survival and poor economic conditions (Medina \& Schneider, 2018; Schneider \& Buehn, 2018). So in this case, the formalisation and growth link might not hold water. In consonance, Kundt (2017a:8) contends that empirical evidence which shows "that formalisation can in fact lead to improved profitability, high incomes, more investments and labour contracts" varies with firm characteristics and firm size, with medium-sized firms benefiting more from these. In agreement, Benjamin \& Mbaye (2020:4) states that "informality inhibits modern management skills and worker training, limiting growth and access to the world market". The researchers further express that as the IS expands, economy wide productivity declines. Loeprick (2009:1) expresses the growth gains argument from the angle of productivity arguing that formalisation would enable the IS firms to emerge from the burden of " informality trap" of lower productivity, lack of access to financing and formal markets which ultimately constrains growth. Reiterating the growth argument, UDSM, DoE (2018:6) depicts the IS as characterised by ease of entry and short lifespan of many entrants often less than 5 years. The activities are said to collapse because of inadequate entrepreneurial skills, low capital, poor equipment and machinery usage, no fixed abode and the impact of taxation. Taxation is greatly pinpointed in the mortality rates of small firms (Ocheni \& Gemade, 2015), especially the multiplicity of these taxes (Ligomeka, 2019; Meagher, 2018; Pimhidzai \& Fox, 2011). 
These arguments make the achievement of these growth gains more sceptical and controversial. Income for expansion, capital adventures as well as for working capital will end up being consumed by taxes and other costs of operating formally thus influencing the economic decisions that operators would have undertaken in the absence of formalisation and taxation, the "deadweight loss of taxation" (Dube, 2018). Rogan (2019) argues that the challenge with the growth gains argument is that, it is based on the tax evasion viewpoint. This what Pimhidzai and Fox (2011:2) described as the "ambivalent view" of the IS with the eyes of tax evaders and the "counterproductive" call for formalisation. These suppositions ignore the role of the sector in in poverty alleviation, employment creation, local economic development and even the provision of inputs to the formal sector or the definition of informality solely basing on the registration for tax purposes (Joshi \& Ayee, 2008; Meagher, 2018).

In some developed countries, the IS is enabled and grown as such and taxed as such, without literally forcing them to formalise. Rogan (2019) is also sceptical of the depiction of formalisation as a rational decision taken by firms after weighing the benefits of formalisation against the costs. These costs and benefits being solely viewed from the perspective of tax compliance and non-tax compliance respectively. It appears to be inadequate to solely link the growth gains to tax compliance. In West Africa, Benjamin and Mbaye (2012) alluded to relatively larger informal firms that are not registered for tax purposes, this signifies growth that is not linked to tax compliance. The question is, Can informality be defined from the non-registration for tax purposes only and growth be linked to registration for tax purposes? The next question will be on which taxes, national taxes only, and ignoring local taxes that are paid by the majority of IS operators (Joshi \& Ayee, 2008; Meagher, 2018; Pimhidzai \& Fox, 2011). Is this a fair assessment and explication of the growth argument? These are possibilities for future research.

Some of the small firms have survived because of their smallness and have no desire to formalise or grow into big firms, their small size allows them the flexibility to manoeuvre, the ease to diversify and the swiftness in decision making, missing in big firms (Ndiweni \& Verhoenen, 2013) Informal firms have adapted to their way of operating (weak management structures, reliance on family capital or financial resources, lack of transparency and dependence on political and social linkages) and survival and others cannot survive the formal way of doing business (Benjamin \& Mbaye, 2020). These firms are productive enough for their size, otherwise forced formalisation might suffocate them due to tax demands, other reporting and accounting requirements, as well as statutory contributions to funds such as development funds, social security burdens, pension funds, benefit funds and medical aid societies among others. Indirectly confirming this potentially pervasive burden resulting from formality, Kundt (2017a:7) posits that "the informal employees might benefit from formalisation through the access to social protection, more adequate contracts, higher wages and reduced vulnerability in case of unemployment or retirement”. Yes it is good for the employee, but is the small financially constrained informal firm equipped to shoulder this increased burden without crumbling? It is important to bear in mind that, high production costs, multiplicity of taxes affecting formal businesses and high tax rates in Africa, coupled with expensive infrastructure, huge capital costs and high formal wages are argued to be what drivers firms into the IS (Benjamin \& Mbaye, 2020; Mbaye \& Benjamin, 2017). How are small informal firms going to cope with these constraints? Focus must not be just on formalisation for tax purposes only. This also ignores the fact that millions of people in African countries are in the IS for the survival motive (Pimhidzai \& Fox, 2011). The IS acts as a safety net for those seeking to survive job losses, retrenchments, poverty and the low skilled as articulated by Hart (1973).

A number of researchers provide evidence that the IS pays taxes despite not to central government, in Uganda, Pimhidzai and Fox (2011:10) avow that “... nano enterprises are not necessarily tax evaders if they do not pay tax at the national level. Rather they pay taxes and fees elsewhere”. In agreement, De Mel, McKenzie, and Woodruff (2013) as cited by Joshi et al. (2013) portend that in as much as the IS does not pay tax to national government they are already doing so in the form licence costs and other charges to local authorities. Meagher (2018) suggests that despite these payments, nothing has changed for this vulnerable sector in terms of growth, recognition for other benefits accruing to formal firms and engagement. Loeprick (2009) and Rogan (2019) advance that the growth gains justification is situated on three key suppositions: (1) the IS circumvents regulation especially taxation laws (2) the firms want to grow, expand and are constrained by capital, lack of funds and requisite training to do so or they remain small because they hide from tax authorities (3) "that there is an appropriate set of policies and packages that will reward firms (appropriately) for registering for tax". Is this really the status quo? Table 3 presents a summary of a few selected studies to highlight the IS taxation-growth advantages puzzle.

The growth gains arguments are complicated, contradictory and mixed. Perhaps in some contexts such as Eastern Europe and West Africa where the large informal firms that are big enough to be formalised and register for tax exist 
Table 3: Summary of selected recent studies on the formalisation and growth motive.

\begin{tabular}{|c|c|c|c|}
\hline Study and Country & Methodology & Findings & Recommendations \\
\hline $\begin{array}{l}\text { (Pimhidzai \& Fox, } \\
\text { 2011), Uganda }\end{array}$ & $\begin{array}{l}\text { Survey of nano- } \\
\text { enterprises }\end{array}$ & $\begin{array}{l}\text { Contrary to the growth gains } \\
\text { argument any further taxation of the } \\
\text { IS (considering they pay license fees, } \\
\text { operating permit fees, cess on and } \\
\text { other market fees), will hurt smaller } \\
\text { firms and increase their vulnerability } \\
\text { to collapse. }\end{array}$ & $\begin{array}{l}\text { Policy makers need to be aware that formalisation } \\
\text { might not lead to higher revenue generation } \\
\text { but to high unemployment, reduced poverty } \\
\text { reduction efforts and economic development } \\
\text { constrained, therefore governments must } \\
\text { carefully weigh the motives of IS taxation, their } \\
\text { effects on other key objectives of government not } \\
\text { just revenue mobilisation. }\end{array}$ \\
\hline $\begin{array}{l}\text { (Ligomeka, 2019), } \\
\text { Zimbabwe }\end{array}$ & $\begin{array}{l}\text { Mixed method approach, } \\
\text { employing face to face } \\
\text { survey interviews, focus } \\
\text { group discussions and } \\
\text { qualitative in-depth } \\
\text { interviews }\end{array}$ & $\begin{array}{l}\text { Taxation of the informal sector is } \\
\text { regressive to the growth, survival and } \\
\text { expansion of these activities as the } \\
\text { bulk of the little income they make } \\
\text { goes to serving tax obligations. }\end{array}$ & $\begin{array}{l}\text { Revisit the "regressive" tax rates and align them } \\
\text { with the ability to pay concept by researching on } \\
\text { the incomes and expenses incurred by the IS as } \\
\text { opposed to just giving a blanket tax rate. }\end{array}$ \\
\hline $\begin{array}{l}\text { (Meagher, 2018), } \\
\text { Nigeria }\end{array}$ & $\begin{array}{l}\text { Interviews with IS } \\
\text { associations and } \\
\text { operators as well as a } \\
\text { survey with randomly } \\
\text { picked IS operators }\end{array}$ & $\begin{array}{l}\text { Taxation impacts negatively on growth } \\
\text { and survival as IS is already paying } \\
\text { some form of tax, but it can also give } \\
\text { the sector the chance to advertise. }\end{array}$ & $\begin{array}{l}\text { Governments should not only focus on } \\
\text { formalisation and registration for tax purposes, } \\
\text { but also seek to empower the sector through } \\
\text { skills development, financing and training. }\end{array}$ \\
\hline
\end{tabular}

Source: Own compilation from various sources

as tabled by Rogan (2019) and Benjamin and Mbaye (2012), the growth advantages can accrue. In SSA, studies point to a coexistence of both the small survivalist motivated firms (dominating) and a few big informal firms, perhaps in this case, the benefits will accordingly vary in relation to firm size as posited by Kundt (2017a). Bruhn and McKenzie (2014), while studying developing countries suggest that formalisation might help the small firms to expand their customer base, improve productivity, turnover and profitability. Governments should enable the IS effectively through access to business services, guidance and other empowerment initiatives.

In light of these observations, it might not be prudent to blindly advocate for taxing the sector on the basis of the growth considerations. Contextualisation becomes key. For large informal firms that already have dimensions typically resembling formal firms, formalisation can reduce inefficiencies and unlock productivity and value. For the small informal firms that cannot survive outright formalisation, without following the "informal-formal dichotomy", their performance, productivity, profitability, growth, survival and employment creation capacity can be ameliorated along their "informality spectrum" (Benjamin \& Mbaye, 2020). Efforts should be made to tax them without forcing them to formalise, otherwise their survival might be threatened.

\subsubsection{Governance Considerations}

Contrary to the other reasons for taxing the IS that have their foundation on the fiscal and regulatory implications, the governance gains perspective provides a more "nuanced" justification (Rogan, 2019) that is outside the common tax and economic scholarly perspectives (Resnick, 2019). In concord, Everest-Phillips and Sandall (2009) and SebeleMpofu (2020) consider the governance-taxation puzzle as one of the weakly explored and misconceived dimension of taxation. The governance benefits rationalisation is underpinned by the implied fiscal exchange contract or implicit social contract between the state and its citizens (taxpayers) (Dickerson, 2014; Meagher, 2018; Resnick, 2019; SebeleMpofu, 2020). This contract is constructed on the key "principles of accountability, legitimacy including mutual trust and encompasses a social norm of paying taxes" (Kundt, 2017a:8). Castaneda, Doyle and Schwartz (2020) argue that literature often neglects that conditions of a working and valid social contract do not hold true in developing countries and that the social contract is fractured. Could taxation be the answer to repairing this fractured contract? Resnick and 
Sivasubramanian (2020) point out that issues to do with the fulfilment of the implicit social contract are closely linked to how reciprocity and procedural justice are addressed by the tax authority and the government. The researchers argue that building trust in government and its actions is critical to the social contract. It still remains debatable whether taxation in developing countries and especially in most African countries could really enhance the social contract. McCulloch, Moerenhout and Yang (2020) affirm the importance of the social contract, arguing that evidence links it to the creation of a norm of honouring tax obligations and a belief that tax evasion is wrong, but postulate evidence that tells a different story pointing to no association between improved or quality of service delivery and voluntary tax compliance in Nigeria. In a contradiction of opinions, Meagher (2018) provides confirmation of a positive impact of accountability, improved service delivery and responsiveness by government on IS tax compliance in Lagos state. Arguments from literature suggest that it is often challenging to build a social contract through taxation in nations where there are abundant natural resources such as oil and citizens depend highly on rent from these or where donor aid is high (Elbahnasawy, 2020; Prichard, Salardi \& Segal, 2018; McCulloch et al., 2020). This perhaps points to the need to reduce donor aid dependence, as it robs the state of a relationship with its citizen based on reciprocity suggesting that citizens become more responsive and accountable to donors. It is important also for future research to investigate how the social contract can be moulded in areas with abundant natural resources such as Nigeria, to allow citizens to benefit but without compromising state legitimacy and IS tax compliance.

Joshi et al. (2014) advance that the absence of fiscal transparency and accountability, which is further coupled with inefficient and ineffective tax administration compels companies to evade tax and hide in the IS. The more generalised negative view of the IS is their depiction as tax evaders (De Mel et al., 2013; Pimhidzai \& Fox, 2011), which basically points to a "vicious cycle" (Everest-Phillips \& Sandall, 2009; Rogan, 2019). In this cycle, because citizens are not happy with the governance quality as it relates to the delivery of public goods and services as well as the way the state engages with them, to show their displeasure they withdraw their contributions through non-tax compliance. The state on the other hand equally fails to deliver on the social contract due to inadequate funding, viciously the cycle continues (Rogan, 2019; Sebele-Mpofu, 2020). A novel emerging perspective is one that strives at repairing the broken social contract (Meagher \& Lindell, 2013), through IS taxation and upgrading it to a "virtuous cycle" (Everest-Phillips \& Sandall, 2009). The researchers reiterate that "Governance and taxation are mutually reinforcing. Governance shapes tax systems, while how taxes are raised influences the creation of effective state institutions and the dynamics of the investment climate and economic growth” (Everest-Phillips \& Sandall, 2009:1). In concurrence, Sebele-Mpofu (2020:4) asserts that "Good governance breeds a fair and balanced tax system and equally a good tax system allows for quality governance”. Everest-Phillips and Sandall (2009:3) portend that the governance implications reasoning in taxation is important for four pertinent reasons: (1) taxation is an important instrument to foster representation (2) the fulfilment of the social contract is important in shaping the taxation cycle outcome, whether a virtuous or vicious cycle emerges (3) transparency, accountability and responsiveness are key pillars of effective tax administration (4) the political economy and its impact on tax morale and compliance is an indispensable reality in any tax system. Government is interested in better tax compliance, yet firms, on the other hand, expect better quality governance together with improved delivery of public goods and services (Benjamin \& Mbaye, 2020). Ibrahim and Ahmad (2017), also explain the social contract not only from the perspective of service delivery, but from the relational angle with tax authorities, pointing out that if the revenue officers are corrupt, unaccountable and not transparent taxpayers will not be willing to comply with tax laws. This suggests certain dimensions to the social contract, the relational angle, the governance quality aspect as well the delivery of public service and goods. These could be explored in-depth as they relate to the social contract and tax compliance.

This was espoused by Keen (2013) and Meagher (2018) as the "New Fiscal Sociology". Three important routes for recrafting the implicit social contract are evident from the various scholars that sought to unpack this nuanced justification of taxing the IS and these are: tax compliance and accountability, legitimacy as well as stakeholder engagement and bargaining (Makochekanwa, 2020; Resnick, 2019; Rogan, 2019; Sebele-Mpofu, 2020). These three will be discussed individually below.

\subsubsection{Tax Compliance and Accountability.}

Accountability is suggestive of "responsibility and answerability" (Otusanya, Adeyeye \& Ovienbor, 2019:1). The accountability of the state to its citizens can be enriched and state building made effective and efficient if citizens are 
responsible for government funding and one such way is through taxation. Accountability can be twofold (Bongwa, 2009; Okoye et al., 2012). Rogan (2019) explains this as the reciprocal engagement by way of a "fiscal exchange hypothesis". Taxpayers exchange tax compliance for accountability and responsiveness in fulfilment of the social contract (Otusanya et al., 2019). Firstly, because citizens are contributing to funding the government, they might demand a more responsive type of governance. Secondly, because citizens are funding the government, the state is more likely to exhibit a higher degree of responsiveness and accountability to its citizens, perhaps also as a way to earn trust and boost tax morale and compliance (Kundt, 2017a; Rogan, 2019; Sebele-Mpofu, 2020). The attainment of the governance objective (through increased accountability and tax compliance) has raised a lot of controversial questions among researchers. Other researchers have queried whether the IS can really hold government accountable for its actions. The scholars have argued that, even in cases where governments have made significant inroads in taxing the sector such as Zimbabwe, Ghana, Nigeria, Tanzania, Kenya and Cameroon (Dube \& Casale, 2016; Kundt, 2017a), government has continued to be unresponsive and unaccountable to this group of taxpayers (Meagher, 2018; Pimhidzai \& Fox, 2011; Sebele-Mpofu, 2020). The social contact continues to be fractured, with government failing to display accountability, responsiveness and citizen engagement to the IS, thus reducing tax morale and increasing tax evasion as citizens "optout of the social contract (Castaneda et al., 2020:1). Re-affirming the violation of the social contract through taxation of the sector, Meagher (2018), as well as Meagher \& Lindell (2013:67), posit that contrary to IS taxation reinforcing public accountability, it appears that it opens novel "avenues for predation". Meagher (2018) alludes to the fact that those IS players that registered for tax purposes in Nigeria, bemoaned the increased harassment from tax officials and other government officers. Could the achievement of the accountability benefits depend on national contexts or perhaps on the nature of governance in a country? It will be interesting for research to explore the conditions under which increased marginalisation and predatory behaviour takes place as well as those under which accountability is fostered.

\subsubsection{Legitimacy}

State legitimacy hinges on the availability of effective government institutions and state capabilities (Bongwa, 2009; Kundt, 2017a). As earlier alluded to in the introductory section that domestic revenue mobilisation has received renewed focus because among other reasons, "state legitimacy, security and national development requires ownership of domestic priorities" and resources (Sebele-Mpofu, 2020:2). The continued ballooning of the IS might be viewed as an indication of lack of perceived value in the engagement with the state in terms of security of property or any other rights. A powerful IS, especially the illegal one, such as drug trafficking rings can pose serious challenges to government control. As a way to address this potential unbecoming situation, IS taxation is considered an ideal avenue to regain legitimacy and put the sector in the eyes of the state (Bongwa, 2009; Okoye et al., 2012). Widening the tax base through incorporation of the IS into the tax net might be much more than just about increasing revenue mobilisation and building a culture of tax compliance, it might also be described as a more effectual way to re-engage citizens with the state (Kundt, 2017a). Intriguing questions arise with regards to legitimacy, whether legitimacy is fostered through IS taxation or destroyed even further due to the quality of governance in many developing countries and SSA in particular (Everest-Phillips \& Sandall, 2009; Sebele-Mpofu, 2020; Topal \& Sahin, 2017). These controversial issues remain scantily explored (Sebele-Mpofu, 2020).

\subsubsection{Stakeholder Dialogue, Engagement and Bargaining}

Prichard (2010) submits that taxation is viewed as a social contract constructed upon bargaining between the state and its taxpayers, as it leans on a quid pro quo. The strengthening of the implicit social contract is argued to have spill-over effects, such as boosting of collective bargaining, political participation, dialogue and stakeholder consultation between government and the IS (Joshi et al., 2014; Kundt, 2017a; Rogan, 2019). Tax becomes a tool to elicit representation (Resnick, 2019). Bargaining can be done through the IS associations and government, thus enhancing public engagement (Kundt, 2017a). Success stories of the fulfilment of this motivation remain limited, but evident in a few countries such as Ghana (Joshi \& Ayee, 2008; Joshi et al., 2014) and Ethiopia (Joshi et al., 2013). In Nigeria, Meagher (2018) states that IS taxation heightens social divisions as opposed to rebuilding the social contract, as stakeholder engagement was evidently weak. While some IS associations made progress in engaging government constructively, the majority were just too weak or fragmented to engage productively. In Zimbabwe, Dube (2014), one of the preliminary 
Table 4: Empirical findings and recommendations on the governance motives from selected studies.

\begin{tabular}{|c|c|c|c|c|}
\hline $\begin{array}{l}\text { Study and } \\
\text { country }\end{array}$ & Methodology & Focus & Findings & Recommendations \\
\hline $\begin{array}{l}\text { (Meagher, } \\
\text { 2018), Nigeria }\end{array}$ & $\begin{array}{l}\text { Interviews with IS } \\
\text { associations and } \\
\text { operators as well as a } \\
\text { survey with randomly } \\
\text { picked IS operators }\end{array}$ & $\begin{array}{l}\text { Taxation and the } \\
\text { Informal economy (IE) }\end{array}$ & $\begin{array}{l}\text { The relationship between taxation, } \\
\text { accountability, political voice and } \\
\text { state-citizen bargaining was found } \\
\text { to be complicated. Taxation of the } \\
\text { IS was found to accentuate the } \\
\text { social injustices. The IS was found } \\
\text { to be largely exposed to extortion, } \\
\text { disorganised and lacking political } \\
\text { power to demand accountability } \\
\text { and transparency on how tax } \\
\text { revenues were spent. }\end{array}$ & $\begin{array}{l}\text { The urgent need to address } \\
\text { historical and contemporary issues } \\
\text { of trust and mistrust between } \\
\text { government and its citizens. In } \\
\text { addition, the state needs to take } \\
\text { into cognisance the novel fiscal } \\
\text { dynamics of relations between } \\
\text { the state and its citizens. Lastly } \\
\text { the IS needs to be empowered not } \\
\text { only financially and through skills } \\
\text { transfer but through respect and } \\
\text { recognition of their associations. }\end{array}$ \\
\hline $\begin{array}{l}\text { (Resnick, } \\
\text { 2019), } \\
\text { Zambia }\end{array}$ & $\begin{array}{l}\text { Questionnaires with } \\
823 \text { informal workers } \\
\text { chosen through a } \\
\text { cluster sampling } \\
\text { approach }\end{array}$ & $\begin{array}{l}\text { Taxation and } \\
\text { Representation in } \\
\text { the IS }\end{array}$ & $\begin{array}{l}\text { Taxation always has a political side } \\
\text { to it. IS not well represented even } \\
\text { after paying taxes, but in some } \\
\text { cases "those demonstrate a greater } \\
\text { affinity towards political candidates } \\
\text { who represent their views. The } \\
\text { paper also established a greater } \\
\text { propensity to pay taxes amongst } \\
\text { those who had access to quality } \\
\text { service delivery. }\end{array}$ & $\begin{array}{l}\text { Decentralisation of tax collection } \\
\text { to the local authorities who are in } \\
\text { close contact with the sector and } \\
\text { better understand their needs and } \\
\text { problems and could address them } \\
\text { through the tax revenues they } \\
\text { collect. }\end{array}$ \\
\hline $\begin{array}{l}\text { (Sebele- } \\
\text { Mpofu, 2020), } \\
\text { Zimbabwe }\end{array}$ & $\begin{array}{l}\text { Questionnaires to and } \\
\text { in-depth interviews } \\
\text { with tax experts and } \\
\text { the tax officers from } \\
\text { ZIMRA }\end{array}$ & $\begin{array}{l}\text { Governance, tax } \\
\text { morale as well as } \\
\text { compliance in the IS }\end{array}$ & $\begin{array}{l}\text { Tax was found not to be an effective } \\
\text { tool to foster representation, } \\
\text { rebuild the social contract or a } \\
\text { platform through which the sector } \\
\text { could constructively bargain or } \\
\text { communicate with the state. } \\
\text { Despite paying presumptive taxes } \\
\text { the IS remained overlooked in } \\
\text { policy crafting. }\end{array}$ & $\begin{array}{l}\text { Governance gains motivation to be } \\
\text { re-examined, efforts made towards } \\
\text { rebuilding of the social contract, IS } \\
\text { state dialogue must be enhanced } \\
\text { through recognition, respect and } \\
\text { engagement of the IS associations } \\
\text { and the IS at large. Service delivery } \\
\text { to be improved as well. }\end{array}$ \\
\hline
\end{tabular}

Source: Own Compilation from various sources

researchers on IS taxation, bemoaned the lack of inclusivity in IS tax policy crafting and recommended IS stakeholder engagement. Munjeyi (2017) reiterated the same, Ligomeka (2019), Newman (2019) and Sebele-Mpofu \& Mususa (2019) emphasised the same. Sebele-Mpofu (2020) found out that despite the existence of organised IS associations such as Bulawayo Passengers Transport Association (BUPTA) and the Zimbabwe Chamber of Informal Economy Associations (ZCIEA), these remained side-lined in policy crafting. Surely six years after the first recommendation, nothing seems to have changed. Similar views were expressed by Meagher (2018) in Nigeria as well as Pimhidzai and Fox in Uganda. Perhaps, Meagher and Lindell (2013:67) were right on the increased room for "predation", further marginalisation and frustration through escalated harassment for some sectors of the IS and positive benefits for others. Could it be that the contradictory outcomes are a result of the power dynamics in these IS associations and organisational structures (Joshi et al., 2014; Kundt, 2017a; Meagher \& Lindell, 2013), political connections perhaps or mobilising ability and sectoral differences? (Meagher, 2018; Prichard, 2010; Rogan, 2019). These are areas open for further investigation. The accomplishment of this objective remains mixed and scantily documented. Otherwise, the strategy aimed at giving the IS a "voice" may further worsen the situation by driving the players to "exit", negatively impacting on governance quality, state bargaining and building" (Sebele-Mpofu, 2020:9). Re-affirming this concern, Pimhidzai and Fox (2011:3) asseverate that the often overlooked sector with a weak voice "ends up paying a disproportionate tax burden". The IS taxation governance relationship demands for comprehensive empirical investigation. 


\subsubsection{Address equity, redistributive justice and reduce inequality}

IS sector taxation might be pursued with the objective of addressing the equity principle of taxation which comes in various dimensions, vertical and horizontal equity (Kundt, 2017a; Ndaka, 2017; Rogan, 2019). Equity was dramatically impacted upon both on the horizontal and vertical perspective. Presumptive taxes violated the ability to pay principle and ignored the profitability of small businesses. Equity is important also in fostering tax justice. Equity will be explored in two facets, the unfairness of taxing only the formal sector which gives an undue competitive edge to the IS over the formal one and from the equity principle with regards to the presumptive tax systems and tax rates (Kundt, 2017a; Ndaka, 2017; Rogan, 2019).

\subsubsection{To minimise the unfair competitive advantage over the formal sector}

The rationale for taxing the IS in this regard is dependent on the argumentation that the informal and formal sector, in most cases produce alike goods that are differentiated at times by quality, packaging and branding or in some cases these are totally similar (Bongwa, 2009; Ndaka, 2017). The formal sector in addition to their other operational costs such as rent, wages and salaries they have to incorporate the tax component (Value Added Tax (VAT) and corporate tax that they are going to pay) (Rogan, 2019). The IS on the other hand, is flexible and has less operational costs and to top it all, no tax obligation. In incorporating the VAT component the formal sector has to make their goods a bit expensive, yet according to Mpapale (2014) and Ndaka (2017), these goods serve possibly a similar purpose, compete for similar resources and markets and use the same infrastructure which is funded by formal taxes. Expostulating the unfairness, Ndaka (2017:83) advances that "This kind of scenario poses a danger of either having the formal business close because of lack of business or join the informal economy where doing business is more lucrative forcing the informal economy to grow even bigger. This is also a form of an injustice that can easily discourage new entrants from entering business formally". Therefore, taxing the IS evens out the undue competitive advantage (Rogan, 2019). This seemingly valid and persuasive argument overlooks the fact that this sector is not totally without taxation or evades tax, it does pay tax at local level through fees, licences and other operating levies (De Mel et al., 2013; Ligomeka, 2019; Pimhidzai \& Fox, 2011; Rogan, 2019). It also contributes to the tax basket through VAT (through paying tax as they purchase products) and others taxes such as customs duty. The formal sector has the liberty to claim VAT input tax that the IS does not enjoy. The formal sector also enjoys deductions, tax incentives and exemptions that are not available to the IS. Where is equity in this case? Does this signify an even playing field?

In addition to these issues of tax injustice, are two other important observations. Firstly, researchers have advanced that the IS does not benefit from public services that the formal sector enjoys, benefits such as health insurance, pension schemes and certification of skills from paying taxes. Secondly, when arguing for better access to financing as a spill-over outcome of IS taxation, literature ignores the precarious, unstable and high-risk nature of IS incomes and collateral decisions, which are important considerations for funding decisions (Benjamin \& Mbaye, 2020). The formal sector appears more privileged than the IS. Conceivably, the rationalisation of taxing the IS basing on the undue advantage perspective, needs to be relooked into with a more balanced assessment, taking into consideration the other costs that are borne by the IS, how the sector aids the operations of the formal sector with inputs as well the informal sector's contribution to poverty alleviation and employment creation. Furthermore, the fact that the IS contributes to taxation especially VAT through purchases and household consumption of goods and services needs to be closely analysed before calling for further taxation of the sector. Otherwise, the blinkered perpetuation of taxation and the unfair advantage arguments might be misinformed.

\subsubsection{Equity in tax systems, their structures and tax rates}

According to Rogan (2019), tax equity largely describes the perceived fairness of the tax rate or part of the income is usually paid by companies and individuals to government as tax. Equity comes in various forms, vertical equity that is more concerned with redistributive justice, those with higher incomes should contribute a greater share to tax. Horizontal equity, on the other hand has to do with treating people with identical situations and incomes in this case in the same manner. People earning or making the same income and even those that are "similarly situated taxpayers (e.g., those with similar family size or business location, access to markets, expenses etc.)" should have exactly the 
same tax obligation (Getachew, 2019). In a simpler expression, those workers in the IS earning the same amount as their counterparts in the formal sector or those firms in the IS and those in the formal sector making identical amounts must be taxed uniformly (Rogan, 2019). The equity argument has often been tabled when advocating for taxation of the IS on the basis that non-taxation of the sector is a violation of the equity principle and a source of unfairness to the formal sector (Joshi et al., 2014; Kundt, 2017a; Ligomeka, 2019). The argument is conceivably reasonable. Notwithstanding the reasonableness of this argument, a major concern is that policy discussions regarding taxing the IS (especially using the presumptive tax systems) have been poorly informed and they focus on the use of presumptions or fixed tax rates, without paying any concern to the operational costs incurred by the IS firms or operators. Bongwa (2009:10) states that "Presumptive taxes are based on some measure of economic activity that proxy for taxable income rather than taxable income itself". The presumptions just use a flat rate or a percentage of income, tax on turnover (TOT) (Mpapale, 2014; Resnick, 2019; Viviers \& Groenewald, 2019), or fixed amount per month or per quarter in Zimbabwe (Ligomeka, 2019; Newman, 2019; Sebele-Mpofu \& Mususa, 2019). Using these presumed amounts, what is the impact on the financial position, profitability and survival of the small firms? Is that turnover enough to cover other operational costs and taxation? Are these presumptions not violating the equity, the ability to pay and economy principles? Is the tax not disproportionate to the income made by some operators? These are some of the questions raised by several tax researchers (Keen, 2013; Ligomeka, 2019; Sebele-Mpofu \& Msipa, 2011; Machemedze et al., 2018). Is there equity if this "sector with the softest voice" is unfairly burdened with a tax burden that does not take into cognisance their ability to pay and the actual net income they make before tax? (Pimhidzai \& Fox, 2011). Are these presumptions not an infringement of tax justice? In some cases these presumptive taxes have been argued to be too high and negatively impacting the survival and growth of small firms. When tax rates are viewed as too high and unfair, the IS players will continue to look for ways to evade tax as expressed by Guttmann (1977:5) "higher and higher taxes drive more and more of the economy underground beyond the reach of the tax collector". The same strategy aimed at addressing equity might be seen as a source of inequity and drive the small firms deeper into the IS.

The argument for using the presumptive taxes is often linked to the sector being difficult to tax, minimising the costs of collection and simplifying the tax system to suit the needs of the IS (Dube \& Casale, 2016; Utaumire et al., 2013). Surprisingly literature provides evidence that this sector is often not consulted or engaged on policy issues affecting them including the design and implementation of tax policy (Meagher, 2018; Mpapale, 2014; Sebele-Mpofu, 2020). In most African countries, tax is far from being a tool to stimulate representation or engagement with the government as credible associations with quality leadership continue to be side-lined by the government (Meagher, 2018; Rogan, 2019; Sebele-Mpofu, 2020:17).In Nigeria, Meagher finds that taxation further heightens inequality and unfair treatment in the IS, contrary to ironing out inequalities. Is this tax justice?

In addition, several studies have pointed to the complexities of tax systems and procedural unfairness or violation of equity. Procedural equity demands that taxpayers be treated in an equal and fair manner (Getachew, 2019), yet studies have shown high handedness and outright harassment or arbitrary tax enforcement by tax authorities when they deal with the IS as compared to when they deal with their formal counterparts (Dickerson, 2014; Heggstad et al., 2011; Sebele-Mpofu \& Msipa, 2020). Meagher (2018) points to unequal treatment by tax authorities of different players in the informal sector in Nigeria with respect to ethnicity and even industry-related. Even when it comes to compliance fairness, the formal sector is usually engaged and educated in various platforms by tax experts and revenue officers on compliance issues or changes in tax policy, yet studies continue to lament the void in tax knowledge in the IS (Dube \& Casale, 2019; Sebele-Mpofu \& Chinoda, 2019). Some players in the IS do not comply with taxes, not because they evade but because they don't know about their tax obligations and even those who are aware of their tax obligation don't know how to go about complying with these (Munjeyi, Mutasa, Maponga, \& Muchuchuti, 2017; Sebele-Mpofu \& Msipa, 2020). Can this not be termed procedural and compliance violation of equity? For the equity motive to be achievable, there is a need for policymakers to evaluate the different dimensions of equity and find ways to design IS tax policy in such a way that it takes into cognisance these dimensions. The concept of equity should be pivotal in tax policy design for the IS. Using TOT has no relation to profitability, even the fixed flat rate or amounts are unfair, and basing on number of employees unfairly treats labor-intensive sectors. Table 5 displays a synopsis of a few selected recent studies, their outcomes and suggestions on the equity rationale. 
Table 5: Summary of selected studies on the equity rationale.

\begin{tabular}{lll}
\hline Study and country & Methodology & Findings \\
\hline $\begin{array}{ll}\text { (Getachew, 2019), } \\
\text { Ethiopia }\end{array}$ & $\begin{array}{l}\text { Survey data and in-depth } \\
\text { interviews with tax } \\
\text { officers and taxpayers }\end{array}$ & $\begin{array}{l}\text { There was a negative perception of } \\
\text { equity as shown by the unfavourable } \\
\text { assessment of the five dimensions of } \\
\text { assessing fairness such as horizontal } \\
\text { equity, procedural fairness, exchange } \\
\text { fairness, compliance and time related. }\end{array}$ \\
& $\begin{array}{ll}\text { Vertical and intergroup fairness were } \\
\text { found to be perceived positively. }\end{array}$
\end{tabular}

(Dube \& Casale, 2019), Zimbabwe

(USDM, DoE, 2018), Tanzania
Mixed method

approach. Combing the representative taxpayer method and interviews with key informants from the tax authority

Desktop research and survey
Presumptive taxes violate the equity principle especially considering no study was conducted on the ability to pay of the IS after the one conducted before its introduction in 2005 .

Presumptive taxes lead to increased inequality as they infringed on the smaller firms who are unable to pay taxes and taxed lesser the bigger informal firms who were supposed to be in higher tax categories. This is as a result of the tax rates, measures used and the diversity in the size of informal firms and income distribution, industry as well as sectoral differences.
Recommendations

Taxpayer perceptions with regards to equity play a crucial role in explaining tax compliance, therefore governments and tax authorities should work towards building a positive view of the state and the tax system. This could be done through transparent tax policy crafting, stakeholder engagement as well as fair and just tax enforcement, without fear or favour.

Tax rates to be revisited and aligned to the profitability of the IS and their ability to pay.

Government should consider these observed variations and probable sources of inequity and address them properly in designing a policy for the IS otherwise, bigger informal firms will always strive not to graduate to formal taxes and the smaller firms' mortality rate will continuously increase as they suffocate from taxes.

Source: Own Compilation from various studies

\subsubsection{Enhance formal sector compliance and boost tax morale}

Tax bases are arguably narrow in developing countries, focusing on the large formal firms and the few visible informal ones (Mpapale, 2014; Resnick, 2019). The legitimate taxpayers would therefore, feel unfairly burdened and the state being unjust in pursuing tax enforcement only on them, ignoring the large and continuously growing IS. This will thus, lower tax morale of these taxpayers, forcing them to find strategies of tax avoidance and evasion or even slowly slide into the IS (Bongwa, 2009; Okoye et al., 2012). Therefore, another fiscal argument for taxing the IS is to improve tax morale through improved tax justice (Resnick, 2019; Rogan, 2019). According Joshi et al. (2014), it remains unclear whether tax morale drives informality or informality diminishes tax morale. Improved tax compliance in the IS will translate to improved tax morale in the formal sector in the literal sense. Whether this happens cannot be established and measured with certainty, but following the peer tax morale dimension supposition, it might be indeed possible that if others successfully evade tax, others would be compelled to do so and the opposite is true (Dickerson, 2014; Luttmer \& Singhal, 2014). Improved tax morale would lead to a broadened tax base in the long term. Thus, perhaps achieving what researchers in taxation of this sector referred to as enhanced culture of tax compliance in the long run (Getachew, 2019; Joshi et al., 2014; Resnick, 2019; Rogan, 2019). These connections remain scantily investigated, especially whether indeed the compliance culture-building gains actually accrue in the long run continues to be debatable. In addition, tax morale has several determinants and dimensions other than peer-driven tax morale insinuated by those arguing for tax in the informal sector in order to improve formal sector tax morale. To affirm this argument, Horodnic (2018) argue that "improving tax morale appears to be associated with modernisation of societies through tackling public sector corruption, strengthening legal environment and a shift towards greater state intervention via higher state revenue generation so as to facilitate redistribution via social transfers to create more equal societies”. Therefore, tax morale is about tax justice as well as how taxpayers evaluate institutional quality, democratic accountability, stability and trust 
in government as well as law and order. Failure to fulfil the implicit social contract of citizens paying tax in exchange for good governance, transparency, accountability and delivery of quality public goods and services, will result in citizens opting out of the social contract by evading tax. It is not just about taxing the IS, but also about government making efforts to address the fiscal exchange contract that will increase tax compliance for both the IS and the formal sector.

\section{Presentation and discussion of findings}

This section summarises the findings in relation to the validity and achievement of the motives towards taxing the IS in developing countries and SSA countries in particular. The findings from the studies are collated, summarised and organised in a manner that allows synthesis of the findings and recommendations in relation to five broad motives identified in the literature review. These are tabulated in such a way that they give a snapshot or provide coherent lens to make sense of the extant knowledge, as suggested by Wee and Banister (2016). Table 6 presents integrated summaries of the findings from the collated studies reviewed in order to give a collective picture of what has been discerned by the researcher from the current body of knowledge on the motives of taxing the IS as well to accentuate the identified gaps. The findings are mixed as researchers converge on certain arguments and differ in others. Researchers are conflicted on whether taxing the IS basing on fairness, equity, growth and building a relationship centred on accountability and responsiveness are valid and attainable motives, with the current IS tax systems (Carroll, 2010; Rogan, 2019, Resnick, 2018, 2020; Resnick \& Sivasubramanian, 2020). These similarities and differences are marked by compelling opinions from researchers justifying why taxation and enforcement should be pursued or not pursued. Mitra (2017), in trying to explicate the considerable contention on the impact of taxation on the IS poses the question "To Tax or Not Tax? When does it Matter for Informality? The identified motives from literature, presented and discussed in this section include: the revenue mobilisation (4.1), formalisation and growth prospects (4.2) governance advantages (4.3), and addressing of the inequality and equity concerns (4.4) and increased tax morale and compliance in the formal sector motives (4.5). The table foregrounds the brief discussion of the findings.

\subsection{The Magnitude of the IS and Revenue Mobilisation}

As outlined earlier, the revenue motive is the most advocated for reason for implementing and enforcing taxation in the IS (Mpapale, 2014; Rogan, 2019). The motive has been overemphasised to a point where other motives have been overlooked (Heggstad et al., 2011; Sebele-Mpofu \& Msipa, 2020). Several studies have explored the cogency and achievement of this objective with the common finding being the fact that despite the implementation of presumptive taxes, very little revenue has been collected so far from this sector in most of these African countries, as presented through the synthesis of findings in Table 6 .

\subsection{Formalisation and Growth}

The informal firms differ in size, behaviour and their challenges to investment differ greatly. While the large informal firms occupying significant sectors of the economy such as food imports, cement manufacturing, construction and pharmaceuticals can withstand the formalisation shocks (Benjamin \& Mbaye, 2020), and benefit greatly from formalising for taxation purposes, the same cannot be said for smaller informal firms. It was evident from the reviewed studies that scholars had different schools of thought and had arrived at varying conclusions. Even though some argued in support of formalisation for tax purposes on the basis of formalisation-induced growth benefits, others offered equally compelling arguments. For example, Fourie (2018) suggests that formalisation perceived from tax registration and deterrent or punitive measures for failure to comply with tax laws may be a narrow conceptualisation of the term. The results of tax collection motivated formalisation can be counterproductive. It may fail to recognise the limited choices of survival faced by the sector. The perspective ignores that there are other ways that can be employed to foster formalisation such as nurturing, "upliftment, transitioning and gradual process" through which the informal firms may be convinced of 
the need and advantages of a gradual movement up the ladder and ultimately becoming formalised small and medium enterprises (Fourie, 2018:468 citing ILO, 2014:35). Research voids are apparent, what should come first, taxation and then formalisation or gradual transitioning into the formal sector coupled with nurturing then taxation. The other question, is would tax registration and payment lead to formalisation benefits? Perhaps taxation would led to the increased growth in informality as opposed to formalisation. What can be deduced is that formalisation must not only be tax-driven, otherwise formalisations that is not adequately planned and informed but only motivated by tax would not yield much cooperation and increased tax contributions. Findings of the formalisation and growth gains rationale have been mixed as presented in the snapshot of the motives, findings, and implications as shown in Table 6.

Table 6: Summary of synthesised findings on the motivations for IS taxation.

\begin{tabular}{|c|c|c|c|}
\hline Motives & Findings & Implications & Studies \\
\hline Revenue & $\begin{array}{l}\text { - Literature showed revenue mobilisation } \\
\text { as the core reason why countries sought } \\
\text { to tax the sector, but the attainment of } \\
\text { the anticipated increase on tax revenue } \\
\text { mobilisation continues to be doubtful. } \\
\text { IS incomes are low and cost of tax } \\
\text { collection high. } \\
\text { Perhaps revenue mobilisation being the } \\
\text { most pivotal motives. Perhaps nations } \\
\text { need to rethink their strategies in the form } \\
\text { of a tree, maybe nurture the sector, invest } \\
\text { in it in terms of support in financing, } \\
\text { training and skills sharing to boost } \\
\text { the sector's productive capacities and } \\
\text { profitability. } \\
\text { The strategy would then yield fruits in } \\
\text { the form of heightened productivity, } \\
\text { healthy financial position and enhanced } \\
\text { profitability and resultantly opportunity to } \\
\text { reap more tax revenues }\end{array}$ & $\begin{array}{l}\text { - This implies more room for research to } \\
\text { investigate avenues to build voluntary tax } \\
\text { compliance in the sector to minimise the } \\
\text { costs of collection. } \\
\text { It can also be worthwhile to explores ways } \\
\text { through which costs of collections can } \\
\text { reduced such as the creation of database } \\
\text { for IS players in the economy, maybe } \\
\text { through engagement of their associations. } \\
\text { Lastly, there is room for further research } \\
\text { on how to nurture the IS operators in a way } \\
\text { that build up their taxable capacities }\end{array}$ & $\begin{array}{l}\text { (Dube, 2014; } \\
\text { Heggstad et al., } \\
\text { 2011; Kundt, 2017a; } \\
\text { Maina, 2016, 2017; } \\
\text { Meagher, 2018; } \\
\text { Newman, 2019; } \\
\text { Rogan, 2019; Sebele- } \\
\text { Mpofu \& Msipa, } \\
\text { 2020) }\end{array}$ \\
\hline $\begin{array}{l}\text { Formalisation } \\
\text { and growth } \\
\text { reasons }\end{array}$ & $\begin{array}{l}\text { - Literature produced contradictory } \\
\text { findings. } \\
\text { There is no agreement on the attainment } \\
\text { and cogency of this motive. Registering for } \\
\text { tax purposes might lead growth of small } \\
\text { firms, while on the other hand, taxation } \\
\text { being a cost, might have negative impact } \\
\text { on growth. } \\
\text { Tax payment may compromise the survival } \\
\text { and growth of small firms by robbing } \\
\text { them of capital and retained earnings for } \\
\text { expansion and business continuity. } \\
\text { The majority of studies allude to the } \\
\text { negative implications as presented in } \\
\text { Table } 3 . \\
\text { What can government do to minimise } \\
\text { the negative impact and to foster the } \\
\text { favourable effects. Perhaps a reduction of } \\
\text { tax rates, alignment of the tax rates to the } \\
\text { incomes or redesign the IS tax systems }\end{array}$ & $\begin{array}{l}\text { - Can taxation of the IS be effectively } \\
\text { advocated for on the basis of the growth } \\
\text { gains emerging from formalisation. } \\
\text { The controversy depicted in findings } \\
\text { shown in the summary in Table } 3 \text { opens } \\
\text { more questions and debates on the } \\
\text { actual impact of IS taxation on the growth } \\
\text { considerations. } \\
\text { Questions linger as to whether the } \\
\text { increased customer base, improved access } \\
\text { to financing, heightened productivity gains } \\
\text { materialise or perhaps these gains are } \\
\text { attainable under certain conditions. What } \\
\text { could possibly be these conditions? } \\
\text { Perhaps the results are varied due to the } \\
\text { methodology used. There is room for } \\
\text { further exploration through empirical } \\
\text { research. }\end{array}$ & $\begin{array}{l}\text { Bruhn \& McKenzie, } \\
\text { 2014; Del Mel et } \\
\text { al, 2013 Ligomeka, } \\
\text { 2019; Pimhidzai \& } \\
\text { Fox, 2011; }\end{array}$ \\
\hline
\end{tabular}


Table 6: Summary of synthesised findings on the motivations for IS taxation.

\begin{tabular}{|c|c|c|c|}
\hline Motives & Findings & Implications & Studies \\
\hline $\begin{array}{l}\text { Governance } \\
\text { advantages }\end{array}$ & $\begin{array}{l}\text { Findings revealed a complex and } \\
\text { contradictory relationship between IS } \\
\text { taxation and the governance gains. } \\
\text { IS taxation could open avenues for } \\
\text { dialogue, engagement and consultation } \\
\text { between the IS taxpayers (citizens) and } \\
\text { the government in some economies, } \\
\text { sectors of the economy or certain groups } \\
\text { of IS operators or those that belong to } \\
\text { certain ethnicity groups yet the same IS } \\
\text { taxation can open more doors for more } \\
\text { harassment, abuse and exploitation of the } \\
\text { IS by government officials and tax officers. } \\
\text { IS taxation is far from being a tool for } \\
\text { representation. }\end{array}$ & $\begin{array}{l}\text { The review established that some } \\
\text { researchers have put forward the historical } \\
\text { breakdown of the social contract as the } \\
\text { reason for the current dysfunctional social } \\
\text { contract and the broken trust between } \\
\text { the state and its citizens. Is it really the } \\
\text { reason? } \\
\text { Several decades later after attainment } \\
\text { of independence and the end of } \\
\text { colonialisation, can we still hold the } \\
\text { historical impact solely responsible for the } \\
\text { broken contract? What have developing } \\
\text { countries and African countries done } \\
\text { to re-build or further destroy the social } \\
\text { contract? } \\
\text { Could it be that the repairment of the social } \\
\text { contract holds true for some sectors of the } \\
\text { IS, those with certain political affiliations } \\
\text { or under certain conditions? These are } \\
\text { notable research gaps. } \\
\text { The IS taxation and repairmen of the social } \\
\text { contract puzzle remains under-explored, } \\
\text { with a lot of grey areas to explore. What } \\
\text { should the two parties (IS and government) } \\
\text { each bring to the table or address to build } \\
\text { a functional fiscal exchange contract on } \\
\text { both the service delivery and relational } \\
\text { reciprocity angles? }\end{array}$ & $\begin{array}{l}\text { (Meagher, 2018; } \\
\text { Resnick, 2019; } \\
\text { Sebele-Mpofu, } \\
\text { 2020; Resnick and } \\
\text { Sivasubramanian, } \\
\text { 2020) }\end{array}$ \\
\hline Equity & $\begin{array}{l}\text { - The review outcomes suggest a } \\
\text { conundrum on the equity motive. } \\
\text { While some researchers to taxing the } \\
\text { IS being a way to strengthen equity by } \\
\text { having all citizens of the state funding } \\
\text { government expenditure for public goods } \\
\text { and utilities through their income-earning } \\
\text { abilities, other researchers empirical } \\
\text { presented results to the contrary. } \\
\text { The presumptive nature of most IS tax } \\
\text { frameworks were a violation of both } \\
\text { vertical and horizontal equity and } \\
\text { perpetuation of inequality. Table } 5 \text { gave an } \\
\text { insight into the controversy. }\end{array}$ & $\begin{array}{l}\text { Questions arise on the reasonableness } \\
\text { of the presumptions and their } \\
\text { appropriateness in taxing the sector. Are } \\
\text { presumptive taxes commensurate with the } \\
\text { equity principle and other principles of } \\
\text { taxation? How else can this sector be taxed } \\
\text { or their taxation be designed in a way that } \\
\text { addresses equity? } \\
\text { The findings and implications point to } \\
\text { the need for more research, analysis and } \\
\text { re-analysis of the IS taxation framework } \\
\text { designs and how they relate to equity. }\end{array}$ & $\begin{array}{l}\text { (Getachew, 2019; } \\
\text { Dube \& Casale, 2019; } \\
\text { Bongwa, 2009; } \\
\text { USDM, DoE, 2018) }\end{array}$ \\
\hline $\begin{array}{l}\text { Building a tax } \\
\text { compliance } \\
\text { culture }\end{array}$ & $\begin{array}{l}\text { - The possibilities of building a tax } \\
\text { compliance culture or further perpetuating } \\
\text { the tax evasion culture are all likely results } \\
\text { as evidenced by the review }\end{array}$ & $\begin{array}{l}\text { Perhaps there is more research on how } \\
\text { to build a tax compliance culture, boost } \\
\text { tax morale and increasing tax morale in } \\
\text { countries with large informal sectors }\end{array}$ & $\begin{array}{l}\text { Dickerson, 2014; } \\
\text { Bongwa, 2009; } \\
\text { Rogan, 2019; Udoh, } \\
\text { 2015; Sebele-Mpofu, } \\
\text { 2021). }\end{array}$ \\
\hline
\end{tabular}




\subsection{Governance Advantages}

While other researchers champion the possibility of governance gains accruing from IS taxation and enforcement (Joshi et al., 2014; Kundt, 2017a; Meagher \& Lindell, 2013), others are very pessimistic on the translation of these probabilities into reality and give evidence of the potentially negative outcomes of the efforts (Lindell, 2010; Meagher \& Lindell, 2013). Interestingly McCulloch et al. (2020) find no association between tax morale and the perceived quality of service delivery and service improvement, which is inconsistent with the findings of most researchers who advocated for taxation as a tool for rebuilding the social contract through reciprocity (Adeyeye \& Otusanya, 2015; Moore, Prichard \& Fjeldstad; Prichard, 2010, 2015). The arguments above are evidence of a controversial and contradictory relationship characterised by consensus among researchers and inconsistencies among some, revealing a possible research gap on the weakly investigated governance gains or social contract building motive towards taxing the IS and the attainability of this objective. From the evidence presented in Table 4, it is apparent that the importance of government accountability and transparency, clear engagement with the IS and fair treatment of the IS taxpayers by tax authorities are silent prerequisites to building of an IS tax system that can achieve the motives behind its consideration. This is also affirmed by Resnick and Sivasubramanian (2020), who allude the possibility of rebuilding the social contract in the IS through tax collection or a further fracturing of the contract. This first scenario could arise if the tax payments are accompanied by reciprocity (both relational and on service delivery) otherwise the scenario could arise where there is no reciprocity that should expectedly complement the payment of tax and citizens are unhappy. It could also arise when taxpayers experience harassment by tax officials, government and local authority officers as a result of registering for tax purposes. The lowered tax morale would further break the contract. Table 6 presents the diverse empirical findings by different researchers on the motives for taxing the sector as well as the controversy surrounding the realisation of the governance gains.

\subsection{Equity Implication}

Researchers have offered diverse contributions and findings in relation to the addressing of equity justifications for taxing the IS. This rationalisation has been characterised by dissension among researchers. Proponents allude to the move being a way to uphold equity and tax justice (Joshi et al., 2014), yet opponents see it as a tax injustice especially the presumptive taxes that violate vertical and horizontal equity (Bongwa, 2009; Getachew, 2019; Meagher, 2018). The presumptions themselves have been described as a violation of equity (Getachew, 2019; Machemedze et al., 2018). The outcomes are disparate and equivocal, as shown in Table 6.

\subsection{Boosting formal sector tax compliance and tax morale}

Results and recommendations have been varying among researchers on this motive of IS tax enforcement (Bongwa, 2009; Getachew, 2019; Rogan, 2019). While the "hypothesised cyclical relationship between taxation and compliance" takes it for granted that taxation of the IS leads to an expanded tax base by fostering a heightened culture of compliance in the formal sector and enriched tax morale (Rogan, 2019), others have questioned the plausibility of this generalised assumption (Resnick, 2019; Sebele-Mpofu \& Msipa, 2020). Tax morale is dependent upon several variables the majority of them which have no link to taxation of the IS (Bitzenis \& Vlachos, 2018; Feld \& Frey, 2007). The rationalisation only looks at one dimension of tax morale, peer reciprocity and ignores the other ones such as service delivery reciprocity perspective, the social contract tax morale dimension as well as the relational reciprocity tax morale component, the quality of governance and stakeholder engagement, or the sense of ownership to decisions made among other tax morale dimensions (Dickerson, 2014; Sebele-Mpofu, 2020). Formal sector tax compliance or non-tax compliance is not just about IS non-tax compliance, there are other numerous determinants of tax morale. To solely put the blame for formal sector tax evasion or noncompliance on the non-taxation of the IS is a rather narrow and biased assessment. 


\section{Conclusions, Limitations, Recommendations and Areas of further research}

The study comprehensively reviewed literature on the various motivations advanced by researchers in favour of IS taxation and enforcement and those against such taxation and enforcement. The paper discussed five main motivations for taxing the IS in Africa. These are: revenue mobilisation, improving growth, strengthening governance, reducing inequality and enhancing tax morale. Several gaps, areas of similarities and differences in the reviewed studies have been highlighted. What can be drawn from literature is that the revenue mobilisation motive is the most topical of all the motives but whether meaningful amount of revenue can be collected from the sector remains doubtful. The attainment of the formalisation and growth gains is equally debatable and contested among researchers. In addition, despite the rebuilding of the social contact motive being crucial, whether it can be done through IS taxation, calls for deeper and more comprehensive and empirical investigation as current evidence exhibits otherwise. In relation to the equity motive, scholars have disagreed on whether presumptive taxes are a fair tax framework and also on whether they ensure both vertical and horizontal equity. Literature reviews normally serve as a foundation for the development of knowledge, help in engendering novel ideas and conceptual directions, together with advancing contemporary avenues for policy and practice. Accordingly, from the findings, the following recommendations are made on future research and how to ameliorate the current IS taxation framework in a more balanced analysis of the motives. Firstly, there is need to consider how much revenue governments can mobilise from the IS and also the trade-off between these motives. How revenue collection from the sector affects growth, governance relationships, and the fulfilment of the social contract and build a compliance culture is a vital evaluation to be made. Secondly, the impact of taxation on the other objectives of government such as employment creation, poverty reduction and economic growth needs to be assessed. Tabling the revenue generation motives and the growth gains stemming from formalisation without paying adequate attention to constraints to growth such as improved access to infrastructure, training, financing as well as skills development in the areas of accounting, marketing, human resource management and information technology will compromise the achievement of these motives and leave them as just elusive dreams. Thirdly, there is a need for efforts to quantify the payments that are made to local authorities by IS firms in order to validate the arguments of regressivity, equity violations and multiplicity of taxes. The local payments and fees might be considered very small but bearing in mind the variability, unstable nature, minuteness and sometimes the seasonality of IS incomes, the amounts might not be small after all and represent a significant portion of these incomes. Ignoring their impact on the IS incomes on the basis that they are small might actually be a distortion of the vulnerability and poverty levels that characterise the sector. Lastly, it is important for the motives to be prioritised in a way that contextualises the prioritisation to the nature of the IS in a country, the legal environment as well as the tax policy in place as these aspects differ considerably on a country to country basis. One of the paper's limitations was that on snowballing, in most of the judgements on both forward and backward snowballing being based on the titles and abstracts of the selected papers, there is a possibility of overlooking papers whose titles, abstract or keywords did not reflect the motives, justifications or reasons for IS taxation yet these could have been addressed inside the papers. Applicability and relevance were key issues in the articles reviewed and objectivity was maintained in order to reduce bias and mistakes in the review. All sides of the coin were explored to give a deeper and open-minded discussion.

Financial Support: This research received no specific grant from any funding agency, commercial or nonprofit sectors.

Conflict of Interests Statement: The authors have no conflicts of interest to disclose. 


\section{References}

Adeyeye, G. B., \& Otusanya, O. J. (2015). The Impact of taxpayers' perception of government accountability, transparency and reduction in fiscal corruption on voluntary tax compliance in Ngeria. International Journal of Economics and Accounting, 6 (3), 276-299.

Adom, D., Hussein, E., \& Agyem, J. (2018). Theoretical and conceptual framework: mandatory ingredients of a quality research. International Journal of Scientific Research, 7, 438-441.

Akintoye, A. (2017). Developing theoretical and conceptual frameworks. Jedm. oauife. edu. ng> uploads, 3(07).

Atawodi, O. W., \& Ojeka, S. (2012). Relationship between tax policy, growth of SMEs and the Nigerian economy. International Journal of Business and Management, 7(13).

Benjamin, N., \& Mbaye, A. A. (2014). Informality, growth, and development in Africa. WIDER WorkingPaper, 52.

Benjamin, N. C., \& Mbaye, A. A. (2012). The Informal Sector, Productivity, and Enforcement in W est A frica: A Firm-level Analysis. Review of Development Economics, 16(4), 664-680.

Benjamin, N., \& Mbaye, A. A. (2020). The Informal Sector in fracophone Africa. The other side of weak Structural transformation. Africa Growth Initiative. Policy Brief.

Bhorat, H., Naidoo, K., \& Ewinyu, A. (2017). Increasing Employment Opportunities: Navigating Africa's Complex Job Market.

Bird, R. M. (2007). Tax challenges facing developing countries: A perspective from outside the policy arena. Available at SSRN 1393991.

Bird, R. M. (2015). Improving tax administration in developing countries. Journal of Tax Administration, 1(1), 23-45.

Bird, R. M., \& Zolt, E. M. (2008). Tax policy in emerging countries. Environment and Planning C: Government and Policy, 26(1), 73-86.

Bitzenis, A., \& Vlachos, V. (2018). Tax morale in times of economic depression: The case of Greece. Advances in Taxation, 25, $173-199$.

Bongwa, A. (2009). Managing Ethiopian Cities II: Informality in Ethiopia: Taxing the Hard to Tax. Retrieved from

Bruhn, M., \& McKenzie, D. (2014). Entry regulation and the formalization of microenterprises in developing countries. The World Bank Research Observer, 29(2), 186-201.

Carroll, E. (2011). Taxing Ghana's informal sector: The experience of women. Occasional Paper, 7.

Dai, N. T., Free, C., \& Gendron, Y. (2016). Interview-based research in accounting 2000-2014: A review. Available at SSRN 2711022.

Dalu, T., Maposa, V. G., Dalu, T., \& Pabwaungana, S. (2013). Awareness and compliance levels of informal traders with regards to their presumptive tax obligations: a case of Harare central business district informal traders. African Journal of Economic and Sustainable Development, 2(4), 297-308.

Daude, C., Gutierrez, H., \& Melguizo, A. (2013). What drives tax morale? A focus on emerging economies. Review of Public Economics, 207(4), 9-40.

De Mel, S., McKenzie, D., \& Woodruff, C. (2013). The demand for, and consequences of, formalization among informal firms in Sri Lanka. American Economic Journal: Applied Economics, 5(2), 122-150.

Dickerson, C. M. (2014). Bringing formal business laws to Cameroon's informal sector: lessons and cautions from the tax law example. Wash. U. Global Stud. L. Rev., 13, 265.

Dube, G. (2014). Informal sector tax administration in Zimbabwe. Public Administration and Development, 34(1), 48-62.

Dube, G. (2018). The design and implementation of minibus taxi presumptive taxes. The Service Industries Journal, 38(11-12), 723-741.

Dube, G., \& Casale, D. (2016). The implementation of informal sector taxation: Evidence from selected African countries. eJTR, $14,601$.

Dube, G., \& Casale, D. (2019). Informal sector taxes and equity: Evidence from presumptive taxation in Zimbabwe. Development Policy Review, 37(1), 47-66.

Elbahnasawy, N. G. (2020). Democracy, political instability, and government tax effort in hygrogen dependent countries. Resources Policy, 65

Everest-Phillips, M., \& Sandall, R. (2009). Linking business tax reform with governance: How to measure success.

Fajnzylber, P., Maloney, W. F., \& Montes-Rojas, G. V. (2009). Releasing constraints to growth or pushing on a string? Policies and performance of Mexican micro-firms. The Journal of Development Studies, 45(7), 1027-1047.

Feld, L. P., \& Frey, B. S. (2007). Tax compliance as the result of a psychological tax contract: The role of incentives and responsive regulation. Law \& Policy, 29(1), 102-120.

Fourie, F. (2018). Enabling the forgotten sector:Informal-sector realities, policy approaches and formailation in South Africa. The South African Informal sector:Creating jobs, reducing poverty. 2018, 439

Getachew, A. (2019). Turnover-Based Presumptive Taxation and Taxpayers' Perceptions in Ethiopia. ICTD African Tax Administration Paper 7. www.opendocs.ids.ac.uk

Hart, K. (1973). Informal income opportunities and urban employment in Ghana. The journal of modern African studies, 11(01), 61-89.

Heggstad, K. K., Ustvedt, T., Myhrvold-Hanssen, T. L., \& Briseid, M. (2011). Towards fiscal self-reliance: Capacity building for domestic revenue enhancement in Mozambique, Tanzania and Zambia (Workshop report).

Hughes, S., Davis, T. E., \& Imenda, S. N. (2019). Demystifying Theoretical and Conceptual Frameworks: A Guide for Students and Advisors of Educational Research. J Soc Sci, 58(1-3), 24-35.

Ibrahim, R., \& Ahmad, A. H (2017). The impact of corruption national development in Nigeria. International Journal of Scientific Research in Social Sciences \& Management Studies, 2 (1), 13-23.

IMF (2011). Revenue Mobilisation in Developing Countries.

Jalali, S., \& Wohlin, C. (2012). Systematic literature: Database searches vs. backwardsnowballing. $6^{\text {th }}$ ACM-IEEE International Symposium on Empirical Software Engineering and Measurement, ESEM, Lund. 
Jedwab, R. \& Dietrich, V. (2019). “The Urban Mortality Transition and Poor country Urbanisation" American Economic Journal of Macroeconomics 11(1):223-275.

Joshi, A., \& Ayee, J. (2002). Taxing for the state? Politics, revenue and the informal sector in Ghana. IDS BULLETIN, 33(3), 90-97.

Joshi, A., \& Ayee, J. (2008). Associational taxation: A pathway into the informal sector? Taxation and State-Building in Developing Countries, 183-211.

Joshi, A., Prichard, W., \& Heady, C. (2013). Taxing the Informal Economy: Challenges, Possibilities and Remaining Questions. IDS Working Papers, 2013(429), 1-37.

Joshi, A., Prichard, W., \& Heady, C. (2014). Taxing the informal economy: The current state of knowledge and agendas for future research. The Journal of Development Studies, 50(10), 1325-1347.

Kanbur, R., \& Keen, M. (2014). Thresholds, informality, and partitions of compliance. International Tax and Public Finance, 21(4), 536-559. Keen, M. (2013). Taxation and development-again. Critical issues in taxation and development, 7, 13-42.

Kundt, T. (2017a). Opportunities and challenges for taxing the informal economy and subnational taxation.

Kundt, T. (2017b). Private Sector Development and Growth in Developing Countries: The Role of Tax Policy and Administration.

Ligomeka, W. (2019). Expensive to be a Female Trader: The Reality of Taxation of Flea Market Traders in Zimbabwe. ICTD working paper

Lindell, I. (2010). Between exit and voice: Informality and the spaces of popular agency. African Studies Quarterly: The Online Journal of African Studies, 11(2-3), 1-124.

Loeprick, J. (2009). Small business taxation: Reform to encourage formality and firm growth (Investment climate in practice: Business taxation No. 1). Washington, DC: World Bank.

Luttmer, E. F., \& Singhal, M. (2014). Tax morale. Journal of Economic Perspectives, 28(4), 149-168.

Mahadea, D., \& Zogli, L-K. J. (2018). Constraints to growth in informal activities and formalisation: A case study of Ghanians slums. The Southern African Journal of Entreprenuership and Small Business Management, (10), 1

Makochekanwa, A. (2020). Informal Economy in SSA: Characteristics, size and tax potential.

Maloney, W. F. (2004). Informality revisited. World development, 32(7), 1159-1178.

Mashiri, E. (2018). Regulating Multinational Enterprises (MNEs) transactions to minimise tax avoidance through transfer pricing: Case of Zimbabwe. A PhD Thesis. UNISA

Mbaye, A. A. \& Benjamin, N. (2017). "How the Interplay between large and small informal firms affect jobs in West Africa". Polese, A., Williams, C.C., Horodnic, I. A. and Bejakovic, P. eds, The Informal Economy in Global Perspective. Palgrave

Mbiliayi, A. (2012). Progress in Taxing the Informal Sector case of Tanzania. TJN-A newsletter. Second quarter, 3.

Mbilinyi, A., \& Mutalemwa, D. (2010). Informal Sector Taxation in Tanzania. TAKNET Policy.

McCulloch, N., Moerenhout, T. \& Yang, J. (2020). Building a Social Contract? Understanding Tax Morale in Nigeria. The Journal of Development Studies, DOI: 10.1080/00220388.2020.1797688

McKenzie, D., \& Sakho, Y. S. (2010). Does it pay firms to register for taxes? The impact of formality on firm profitability. Journal of Development Economics, 91(1), 15-24.

McKenzie, D. J., \& Paffhausen, A. L. (2017). Small firm death in developing countries: The World Bank.

Meagher, K. (2018). Taxing times: Taxation, divided societies and the informal economy in Northern Nigeria. The Journal of Development Studies, 54(1), 1-17.

Meagher, K., \& Lindell, I. (2013). ASR FORUM: ENGAGING WITH AFRICAN INFORMAL ECONOMIES: SOCIAL INCLUSION OR ADVERSE INCORPORATION?: Introduction. African Studies Review, 56(3), 57-76.

Medina, L., \& Schneider, F. (2018). Shadow economies around the world: what did we learn over the last 20 years?

Mitra, S. (2017). To tax or not to tax? When does it matter for informality? Economic Modelling, 64, 117-127.

Moore, M. (2020). What is Wrong with African Tax Administration? ICTD Working Paper 111, ICTD. Accessed from https://opendocs.ids.ac.uk/ opendocs/bitsream/handle/

Moore, M., Prichard, W. \& Fjeldstad, O,-H. (2018). Taxing Africa: Coercion, Reform and Development (First Edition). London: Zed Books

Morse, J. M. (2015). Data were saturated: Sage Publications Sage CA: Los Angeles, CA.

Mpapale, C. (2014). Broadening the Tax Base in Kenya: The Case of Informal Sector. The East Africa Tax and Governance Network (EATGN), 1-22.

Mpofu, F. Y. (2021). Review Articles: A Critical Review of the Pitfalls and Guidelines to effectively conducting and reporting reviews. Technium Social Sciences Journal 18, 550-574, 2021.

Munjeyi, E., Mutasa, S., Maponga, S., \& Muchuchuti, K. (2017). The Informal Sector Tax Revenue Potential: A Case of Zimbabwe'. Research Journal of Finance and Accounting, 8(8).

Nakamba-Kabaso, P., \& Phiri, S. C. (2012). Taxation of the informal sector in Zambia.

Ndaka, A. K. (2017). Informal sector and taxation in Kenya: Causes and effects. International Journal of Law, Humanities and Social Science, 1(4), 77-86.

Ndiweni, E., \& Verhoeven, H. (2012). The rise of informal entrepreneurs in Zimbabwe: Evidence of Economic growth or failur of economic policies? African Journal of Accounting, Auditing and Finance, 2 (3):260-276.

Newman, W. (2019). AN EVALUATION OF THE EFFECTIVENESS OF PRESUMPTIVE TAX ADMINISTRATION ON REVENUE COLLECTION BY ZIMRA: A CASE STUDY OF THE COTTAGE INDUSTRY IN HARARE (2011-2018). Academy of Entrepreneurship Journal, 25(2).

Ocheni, S., \& Gemade, T. (2015). Effects of multiple taxation on the performance of small and medium scale business enterprises in Benue State. International Journal of Academic Research in Business and Social Sciences, 5(3), 345. 
Ogbuabor, J. E., Aneke, G., \& Ogbuabor, C. (2014). Informal Sector and Domestic Resource Mobilization in Nigeria: A Community Taxation Option.

Ogbuabor, J. E. \& Malaolu, V. A. (2013). Size and Causes of the Informal Sector of the Nigerian Economy: Evidence from Error Correction Mimic Model. Journal of Economics and Sustainable Development, 4 (1).

Ojeka, S. (2011). Tax policy and the growth of SMEs: Implications for the nigerian economy. Research Journal of Finance and Accounting, 2(2).

Okoye, P., Akenbor, C. O., \& Obara, L. C. (2012). Promoting sustainable tax compliance in the informal sector in Nigeria. AFRREV IJAH: An International Journal of Arts and Humanities, 1(1), 40-54.

Otusanya, O. J., Adeyeye, G. B., \& Ovienbour, L. (2019). Informal Sector Taxpayers' Perception of Influence of Government Accountability On Voluntary Tax Compliance and the moderating Role of Fiscal Exchange. International Journal of Accounting and Finance (IJAF), 8 (2).

Padron, K. (2018). The literature Review. Florida Atlantic University Libraries.

Perry, G., Maloney, W., Arias, O., Fajnzylber, P., Mason, A., \& Saavedra, J. (2007). Informality: Exit and Exclusion, World Bank Latin America and Caribbean Studies. World Bank, Washington DC.

Pfister, M. (2009). Taxation for investment and development: An overview of policy challenges in Africa. Paper presented at the A Background paper to the Ministerial Meeting and Expert Roundtable of NEPAD-OECD Africa Investment Initiative.

Phiri, S. C. and Nakamba-Kabaso, (2012). Taxation of the Informal Sector in Zambia. Zambian Institute of Policy Analysis and Researc (ZIPAR). https://www.africaportal.org/publications/taxation

Pimhidzai, O., \& Fox, L. (2011). Taking from the poor or local economic development: the dilemma of taxation of small informal enterprises in Uganda. World Bank Africa Regional Project on Improving the Productivity and Reducing Risk of Household Enterprises, Washington DC.

Prichard, W. (2009). Taxation and Development in Ghana: Finance, equity and accountability.

Prichard, W. (2010). Taxation and state building: Towards a governance focused tax reform agenda. IDS Working Papers, 2010(341), 01-55.

Prichard, W. (2015). Taxation, Responsiveness and Accountability in Sub-Saharan Africa: Th dynamics of tax bargaining. Cambidge:Cambridge University Press

Prichard, W., Salardi, P., \& Segal, P. (2018). Taxation, non tax revenue and democracy:New evidence using new cross country data. World Development, 109, 295-312.

Prichard, W., \& Van den Boogaard, V. (2017). Norms, power, and the socially embedded realities of market taxation in Northern Ghana. African Studies Review, 60(1), 171-194.

Resnick, D. (2019). Tax compliance and representation in Zambia's informal economy (Vol. 1794): Intl Food Policy Res Inst.

Resnick, D. (2020). Taxing Informality: Compliance and Policy Preferences in Rban Zambia. The Journal of Development Studies, 1-23.

Resnick, D. \& Sivasubamanian (2020). Negotiating the Social Contract in Urban Africa: Informal food traders in Ghanian cities (Vol. 1938). Int Food Policy Res Inst.

Rogan, M. (2019). Tax Justice and the Informal Economy: A Review of the Debates. WIEGO

Schneider, F., \& Buehn, A. (2018). Shadow economy: Estimation methods, problems, results and open questions. Open Economics, 1(1), 1-29.

Sebele-Mpofu, F. Y. (2020). Governance quality and tax morale and compliance in Zimbabwe's informal sector. Cogent Business \& Management, 7(1), 1794662.

Sebele-Mpofu, F. Y., \& Chinoda, T. (2019). Tax Knowledge, Tax System Complexity Perceptions and Attitudes of the Commercial Sugarcane Farmers and Their Influence on Tax Compliance in the Lowveld Area, Zimbabwe. International Journal of Innovative Science and Research, 4(4), 407-418.

Sebele-Mpofu, F. Y., \& Msipa, C. (2020). Feasibility of Administering Informal Sector Taxation: Approaches and Hurdles. A Case of the Informal Sector in Bulawayo, Zimbabwe. International Journal of Innovative Science and Research, 5(2), 193-208.

Sebele-Mpofu, F. Y., \& Mususa, A. How Successful is Presumptive Tax in Bringing Informal Operators into the Tax Net in Zimbabwe? A Study of Transport Operators in Bulawayo. International Journal of Innovative Science and Research, 4(3), 79-89.

Spotlight, A. T. (2012). Taxation and the informal sector. Tax Justice Network.

Snyder, H. (2019). Literature review as a research methodology: An overview and guidelenes. Journal of Business Research, 104,333-339.

Topal, M. H., \& Sahin, M. Governance Quality and Taxation: A Panel Co-Integration Evidence for OECD Countries.

University of Dar Es Salaam, Department of Economics (2018): The Nexus between Taxation of the Informal Sector and Inequality in Tanzania. www.policyforum-tz.org

Udoh, J. E (2015). Taxing the Informal Economy in Nigeria: Issues, Challenges and Opportunities. International Journal of Business and Social Science, 6, 160-176

Utaumire, B., Mashiri, E., \& Mazhindu, K. (2013). Effectiveness of presumptive tax system in Zimbabwe: Case of ZIMRA Region one. Research Journal of Finance and Accounting, 4(7), 114-120.

Viviers, H., \& Groenewald, L. (2019). Turnover tax: worthwhile or waste of time?: turnover tax. TAXtalk, 2019(75), 10-12.

Wee, B. V., \& Banister, D. (2016). How to Write a Literature Review Paper?, Transport Reviews, 36:2, 278-288, DOI: 10.1080/01441647.2015.1065456 